UNIVERSIDADE DE SÃO PAULO

FACULDADE DE ECONOMIA, ADMINISTRAÇÃO E CONTABILIDADE DEPARTAMENTO DE ECONOMIA PROGRAMA DE PÓS-GRADUAÇÃO EM ECONOMIA

CRÉDITO E EMPREENDEDORISMO: CONFRONTANDO EVENTOS AGREGADOS E MICRODADOS

Bruno Outa Gasperini

Orientador: Prof. Dr. Gabriel de Abreu Madeira

SÃO PAULO

2010 
Prof. Dr. João Grandino Rodas

Reitor da Universidade de São Paulo

Prof. Dr. Reinaldo Guerreiro

Diretor da Faculdade de Economia, Administração e Contabilidade

Prof. Dr. Denisard Cnéio de Oliveira Alves

Chefe do Departamento de Economia

Prof. Dr. Dante Mendes Aldrighi

Coordenador do Programa de Pós-Graduação em Economia 
BRUNO OUTA GASPERINI

\section{CRÉDITO E EMPREENDEDORISMO: CONFRONTANDO MICRODADOS E EVENTOS AGREGADOS}

Dissertação apresentada ao Departamento de Economia da Faculdade de Economia, Administração e Contabilidade da Universidade de São Paulo como requisito para a obtenção do título de Mestre em Economia.

Orientador: Prof. Dr. Gabriel de Abreu Madeira

\section{SÃO PAULO}


FICHA CATALOGRÁFICA

Elaborada pela Seção de Processamento Técnico do SBD/FEA/USP

Gasperini, Bruno Outa

Crédito e empreendedorismo : confrontando microdados e eventos agregados / Bruno Outa Gasperini. - São Paulo, 2010.

$56 \mathrm{p}$.

Dissertação (Mestrado) - Universidade de São Paulo, 2010.

Orientador : Gabriel de Abreu Madeira.

1. Crédito 2. Empreendedorismo 3. Desenvolvimento econômico

I. Universidade de São Paulo. Faculdade de Economia, Administração e Contabilidade II. Título.

$\mathrm{CDD}-332.7$ 
À minha mãe, Maria. 


\section{AGRADECIMENTOS}

Primeiro, gostaria de agradecer às pessoas que eu mais amo. À minha esposa, Karla, por ser minha companheira nessa jornada e tomar os meus sonhos como os dela. À minha mãe, Maria, por ter sempre me apoiado em todos os momentos da minha vida. Muito obrigado por terem sempre acreditado em mim.

Gostaria de agradecer ao meu orientador, Gabriel Madeira, por ter sempre se mostrado bastante solícito para conversas e (muitas) dúvidas. Fui bastante feliz por ter tido um orientador sempre interessado em discutir novas idéias.

Agradeço também aos professores Fernando Botelho, Marcos Rangel e Ricardo Madeira por terem influência direta sobre a minha formação acadêmica. Além disso, sou grato pelas sugestões dadas às versões preliminares deste trabalho.

Agradeço aos meus amigos do IPE-USP que mantiveram um ótimo ambiente de estudos e propiciaram muitos momentos engraçados durante esses 2 anos e meio. A sala de café era o encontro dos craques. Entre eles, sou grato aos amigos Dejanir Henrique, Eduardo Jardim, Leonardo Gonzalez, Ricardo Sabbadini e Silvio Michael que, em algum momento, leram versões preliminares, discutiram idéias, ajudaram a resolver integrais, auxiliaram com a base de dados e com rotinas no MATLAB.

Por fim, agradeço ao apoio financeiro do CNPq. 


\section{RESUMO}

Enquanto microeconomistas apontam para uma correlação positiva entre empreendedorismo e riqueza, macroeconomistas enfatizam que existe uma correlação negativa entre empreendedorismo e desenvolvimento (acumulação de riqueza). Este trabalho apresenta um modelo que reconcilia esses dois fatos aparentemente contraditórios. Tomando com base um modelo padrão de empreendedorismo e restrição de crédito, como em Evans e Jovanovic (1989), adicionamos a este modelo uma condição de equilíbrio no mercado de trabalho. Tal modificação gera a coexistência dessas duas correlações de sentidos opostos. A correlação negativa entre empreendedorismo e desenvolvimento existe mesmo que o mecanismo gerador do desenvolvimento seja a diminuição da restrição de crédito. $O$ modelo prevê que a proporção de empreendedores diminui para a fração rica e que empreendedorismo pode aumentar para a fração pobre da população. Além disso, mostra-se que tais predições são consistentes com dados brasileiros recentes. 


\begin{abstract}
While microeconomists show a positive correlation between entrepreneurship and wealth, macroeconomists emphasize that there is a negative correlation between entrepreneurship and development (wealth accumulation). This work presents a model that brings together these two apparently conflicting facts. Departing from a standard entrepreneurship setup, as in Evans and Jovanovic (1989), our model adds a market clearing condition in the labor market. This addition to the standard model allows for the coexistence of these two correlations of opposite directions. Such negative correlation between entrepreneurship and development can be obtained even when development is generated by relaxing the credit constraint. The model predicts that the proportion of entrepreneurs decreases for the rich and that entrepreneurship can increase for the poor. Further, it is shown that such predictions are consistent with recent Brazilian data.
\end{abstract}




\section{SUMÁRIO}

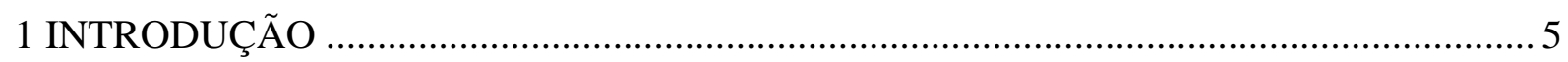

2 MODELO.

2.1 Preferências e tecnologia ………………………….......................................

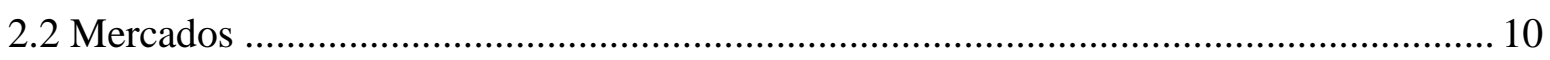

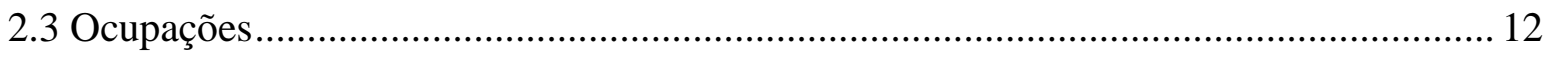

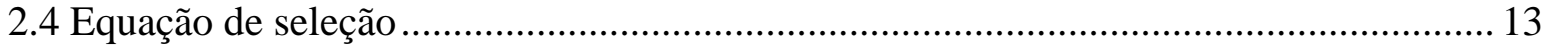

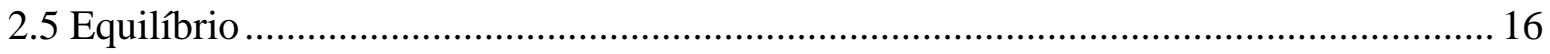

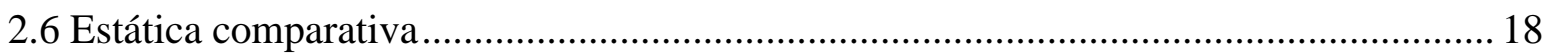

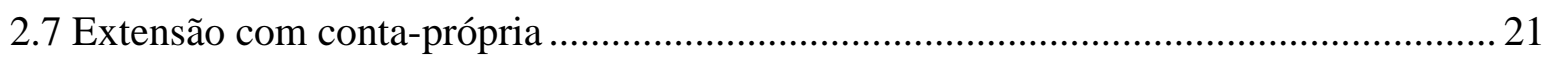

3 ALGUMAS EVIDÊNCIAS EMPÍRICAS DOS DADOS BRASILEIROS ..........................24

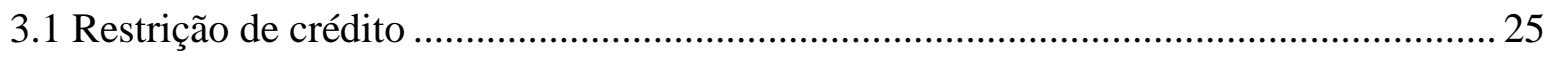

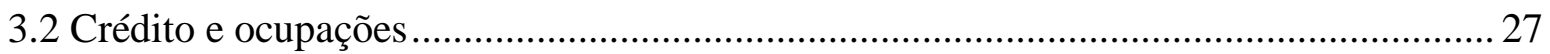

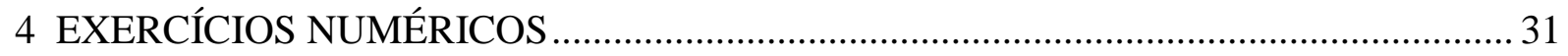

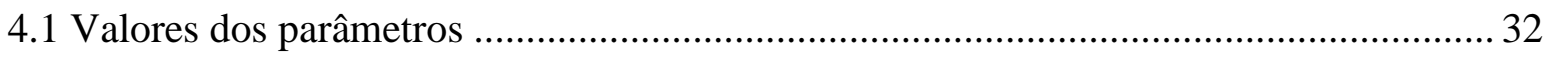

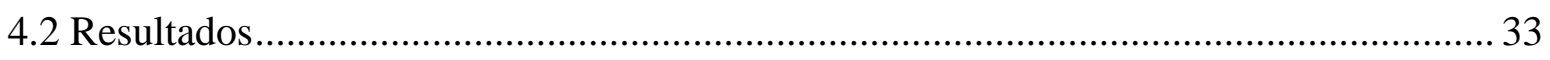

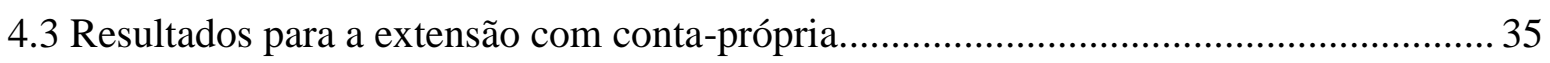

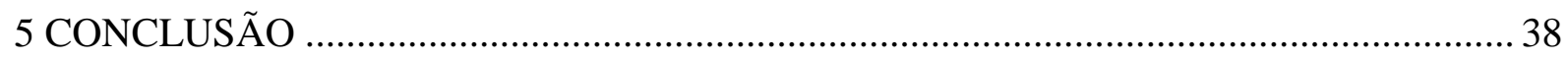

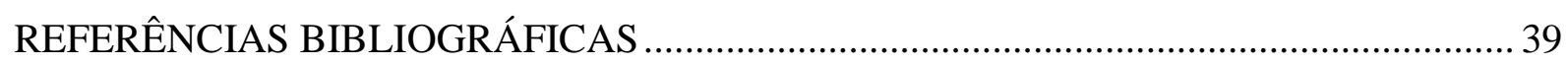

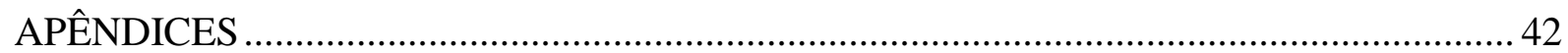

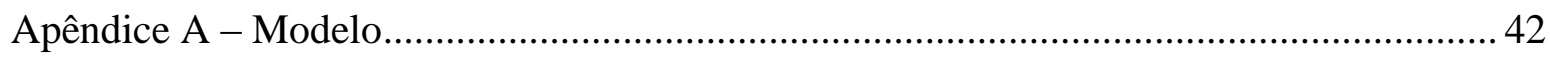

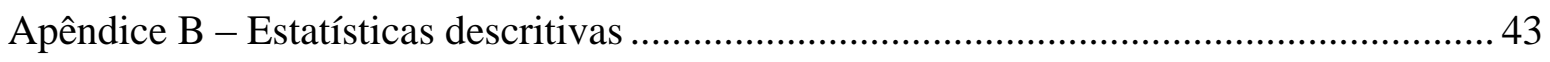

Apêndice C - Medida de riqueza ................................................................................ 44

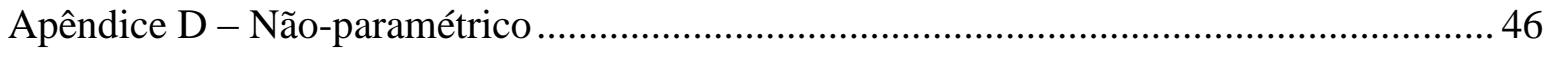

D.1 - Perfil não-paramétrico de riqueza ........................................................................... 46

D.2 - Regressão não-paramétrica entre empreendedorismo e riqueza ………………….... 47

D. 3 - Regressão não-paramétrica entre empreendedorismo e riqueza para jovens........... 48

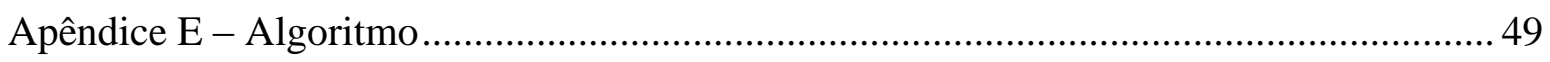




\section{LISTA DE FIGURAS}

Figura 1: Distribuição de ocupações no espaço talento-riqueza ............................................. 16

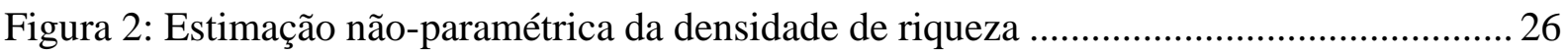

Figura 3: Regressão não-paramétrica entre as ocupações e riqueza ....................................... 27

Figura 4: Operações de crédito ao setor privado como proporção do PIB para o período 1995-

2008.

Figura 5: a) Proporção de Empreendedores, b) Proporção de Conta-Própria e c) Proporção de Trabalhadores para o período 1995-2008.

Figura 6: a) Proporção de Empregadores com riqueza abaixo da mediana; b) Proporção de Empregadores com riqueza acima da mediana para o período 1995-2008 ….......................... 30

Figura 7: Efeito do aumento de $\lambda$ no modelo EJ tradicional.................................................. 34

Figura 8: Efeito do aumento de $\lambda$ no modelo EJ modificado............................................... 35

Figura 9: Efeito do aumento de $\lambda$ sobre empreendedorismo por faixa de riqueza................... 35

Figura 10: Proporção de Empreendedores pela riqueza........................................................ 37

Figura 11: Proporção de Trabalhadores pela Riqueza ........................................................... 37

Figura 12: Proporção de Conta-Própria por faixa de riqueza.................................................. 37

Figura D1: Perfil não-paramétrico de riqueza separado por ano

Figura D2: Regressão não-paramétrica entre empreendedorismo e riqueza separada por ano

Figura D3: Regressão não-paramétrica entre empreendedorismo e riqueza para pessoas jovens separada por ano .48 


\section{LISTA DE TABELAS}

Tabela 1: Regressão das ocupações em dummies 29

Tabela 2: Regressão das ocupações em uma tendência linear 29

Tabela 3: Regressão da proporção de empreendedores com riqueza abaixo e acima da mediana em dummies 30

Tabela 4: Regressão da proporção de empreendedores com riqueza abaixo e acima da mediana em uma tendência linear.

Tabela 5: Aumento de $\boldsymbol{\lambda}$ sobre o salário e as ocupações.

Tabela 6: Aumento de $\lambda$ sobre o salário e as ocupações no modelo estendido. 36

Tabela B1: Estatísticas descritivas separadas por ocupações 43 


\section{INTRODUÇÃO}

Uma grande literatura enfatiza as restrições de crédito como um fator fundamental sobre a decisão de ser empreendedor. O canal é como segue: a atividade empreendedora envolve investimento em capital que deve ser financiado pela riqueza própria ou por recursos emprestados. Sob restrições de crédito, indivíduos desprovidos de recursos são impedidos de tomar escolhas eficientes. Assim, estes ou se tornam trabalhadores assalariados, mesmo tendo grande potencial para abrir um negócio, ou, mesmo que se tornem empreendedores, não conseguem investir em escala ótima.

Dessa forma, um sintoma das restrições de crédito pode ser encontrado ao se estudar o efeito da riqueza inicial sobre empreendedorismo. Caso o mercado de crédito fosse perfeito, indivíduos abririam negócios apenas com base na lucratividade do projeto, independentemente de sua riqueza. Se necessário, eles poderiam obter qualquer quantidade de recursos para o investimento. Esse raciocínio sugere um meio de evidenciar a existência de restrições financeiras: quando estas são importantes, cria-se um link entre riqueza e empreendedorismo. A correlação positiva entre riqueza inicial e a probabilidade de abrir um negócio sugere a existência de restrições de crédito ${ }^{1}$.

Nessa literatura, o papel das imperfeições no mercado de crédito é documentado por estudos que se valem de diferentes metodologias. Paulson e Townsend (2004) encontram, através de análises de forma reduzida e regressões não-paramétricas, que pessoas com maior riqueza inicial têm maior probabilidade de se tornarem empreendedoras na Tailândia. Para lidar com o possível problema de endogeneidade entre riqueza e empreendedorismo, Holtz-Eakin, Joulfaian e Rosen (1994) e Blanchflower e Oswald (1998) utilizam herança como um instrumento para riqueza e também encontram a evidência de restrições financeiras nos Estados Unidos. Utilizando modelos estruturais, Evans e Jovanovic (1989) e Buera (2008) também encontram evidências de restrições financeiras para os Estados Unidos. A principal

\footnotetext{
${ }^{1}$ Restrições financeiras também podem ser sugeridas caso se evidencie que firmas fossem mais lucrativas se pudessem tomar um volume maior de empréstimo. Fazzari, Hubbard e Petersen (1988), Paulson e Townsend (2004) e Banerjee e Duflo (2006) encontram essas evidências para Estados Unidos, Tailândia e Índia, respectivamente.
} 
mensagem que temos dessa literatura é a existência de uma relação positiva entre riqueza e empreendedorismo ${ }^{2}$.

Diferentemente, a relação entre riqueza e empreendedorismo toma outra direção sob a perspectiva macro. A partir de dados da Organização Internacional do Trabalho para o período 1988-1993, Gollin (2008) aponta que países mais ricos têm menor proporção de empreendedores: por exemplo, a razão empreendedor/trabalhador nos Estados Unidos é 0,019 e na França é 0,059, enquanto para a Nigéria e Bangladesh essa mesma razão é 0,780 e 0,792, respectivamente. Gollin (2008) também mostra que o mesmo padrão pode ser observado na trajetória de crescimento de um país: dados japoneses atestam o aumento do PIB per capita acompanhado pela diminuição da razão empreendedor/trabalhador durante o período $1930-1992^{3}$.

A partir de uma versão modificada do modelo de Lucas (1978), Gollin (2008) propõe um modelo dinâmico, sem restrição de crédito, que explica essa relação negativa entre empreendedorismo e crescimento pela diferença na produtividade e pela heterogeneidade de um fator fixo na produção. $\mathrm{O}$ fator fixo nesse modelo, talento empreendedor, faria com que o capital fluísse para os agentes mais talentosos, que possuem maior produtividade marginal. Essa acumulação de capital faria com que o trabalho fosse mais produtivo, aumentando o salário e os ganhos de ser trabalhador. Em equilíbrio, apenas os indivíduos com talento maior que certo nível se tornam empreendedores. Assim, ao longo do tempo, o processo de desenvolvimento de uma economia seria caracterizado por uma maior proporção de trabalhadores e uma menor proporção de empreendedores. Já a diferença existente na razão empreendedor/trabalhador entre os países pode ser explicada por diferenças nas produtividades: supondo mercados perfeitos, o capital se moveria entre as diversas economias, fluindo para os países com maior produtividade. O modelo calibrado é consistente com os fatos observados.

A interessante mensagem que temos desses estudos é que uma literatura micro-orientada aponta para uma correlação positiva entre riqueza e empreendedorismo (quando a análise se restringe dentro de um país e em um determinado instante de tempo), enquanto uma literatura macro-orientada sugere uma relação negativa entre desenvolvimento/crescimento

\footnotetext{
${ }^{2}$ Apesar de não encontrarem evidências de restrições financeiras para a maior parte dos dados americanos, Hurst e Lusardi (2004) documentam a relação positiva para o quintil mais rico da amostra.

${ }^{3}$ Ver Gollin (2008) para consultar informações sobre a razão empreendedor/trabalhador para mais de 50 países e a evolução dessa mesma razão para dados japoneses.
} 
(acumulação de riqueza) e empreendedorismo (quando se analisam dados cross-country ou dados para um único país ao longo do tempo).

Este trabalho tem como objetivo conciliar essas duas literaturas ao propor um modelo em que se mostra possível a coexistência dessas correlações de sentidos opostos. Os estudos mencionados não admitem essa coexistência. Gollin (2008) não permite uma correlação positiva, uma vez que não se supõe nenhuma imperfeição no mercado de crédito. De maneira oposta, um modelo simples de empreendedorismo, como Evans e Jovanovic (1989) - EJ daqui em diante - também não admite essas duas correlações. Apesar de levar em conta a restrição de crédito, o modelo EJ não possui nenhum mecanismo que explique a correlação negativa. Para contemplar essas duas correlações, este trabalho propõe uma reformulação do modelo EJ que adiciona uma condição de equilíbrio no mercado de trabalho. Com esta simples reformulação, o modelo cria um canal que pode gerar a correlação negativa. E a origem deste canal é justamente a diminuição da restrição de crédito.

Esse canal, a princípio, parece ser contraditório. A existência da restrição de crédito leva indivíduos a optarem por outras ocupações devido à falta de recursos próprios. Então, como o afrouxamento da restrição de crédito pode gerar a queda, ao invés do aumento da proporção de empreendedores na economia? A diminuição da restrição de crédito não deveria levar indivíduos desprovidos de crédito a optar pelo empreendedorismo?

Intuitivamente, o efeito é o seguinte: menor restrição de crédito aumenta a demanda por capital, aumentando a produtividade do trabalho, o que, em equilíbrio, aumenta o salário e os ganhos de ser trabalhador. Após a mudança, apenas indivíduos suficientemente ricos e talentosos optarão pelo empreendedorismo. Devido a este mecanismo, uma redução da restrição de crédito pode diminuir a proporção de empreendedores. Nesse sentido, a explicação para esse efeito segue, em parte, Gollin (2008). A diferença reside na origem do canal. Para Gollin (2008), a diminuição de empreendedorismo se dá pelo aumento de produtividade, enquanto que a origem aqui é o afrouxamento da restrição de crédito.

Todavia, esses dois canais não são desconectados. É nesse sentido que este trabalho pode ser relacionado a uma nova e crescente literatura sobre má alocação de recursos, como em Banerjee e Duflo (2005), Jeong e Townsend (2007), Hsieh e Klenow (2009), Banerjee e Moll (2010) para citar alguns. Esses trabalhos apontam que diferenças de produtividade das 
economias podem ser explicadas em grande parte pela má alocação e não apenas pela falta de recursos. Este trabalho mostra que uma redução da restrição de crédito, que diminui a má alocação e aumenta a produtividade da economia leva a uma queda da proporção de empreendedores na economia.

Ainda, ao tornar endógena a determinação de salário, conseguimos mostrar que existe um efeito não trivial do aumento do crédito sobre a escolha ocupacional dos agentes: a proporção de empreendedores diminui para a fração mais rica e pode subir para a fração mais pobre da economia. Esses dois efeitos combinados podem diminuir a proporção de empreendedores, sendo necessariamente verdade caso exista uma fração suficiente de agentes com riqueza acima de certo nível. Assim, o efeito final depende fundamentalmente da distribuição de riqueza e talento na economia.

O modelo é explorado quantitativamente utilizando microdados brasileiros para o período 1995-2008. Dois fatos interessantes acontecem nesse período, o que torna o caso brasileiro bastante propício para se analisar as predições do modelo: um notável aumento de crédito, com políticas de fomento, como, por exemplo, expansão de microcrédito e crédito consignado, ao mesmo tempo em que se depara com uma queda da proporção de empreendedores ${ }^{4}$ nos microdados brasileiros. Além disso, ao estratificar os indivíduos pela riqueza, notamos que ocorre um aumento de empreendedores para os indivíduos com riqueza abaixo da mediana e uma queda para indivíduos acima da mediana. Dessa forma, as predições do modelo são consistentes com os fatos vistos nos microdados brasileiros.

Por fim, uma extensão do modelo é proposta ao se adicionar explicitamente a atividade contaprópria como outra ocupação no modelo. Essa decisão se deve por dois motivos. Primeiro, pelo fato de uma fração relevante dos indivíduos optarem por essa atividade. Segundo, e mais importante, pela atividade conta-própria, em países em desenvolvimento, ser bastante diferente de empreendedorismo, sendo considerada uma forma de desemprego disfarçada, como aponta Mondragón-Vélez e Peña-Parga (2008). Ao enriquecer o modelo, mostramos que as principais predições do modelo base não são alteradas com essa adição.

\footnotetext{
${ }^{4}$ Definimos empreendedores como indivíduos que possuem negócios e empregam outras pessoas. A Subseção 3.1 trata acerca dessa definição.
} 
A contribuição desse trabalho pode ser resumida de três formas. Primeiro, por propor um diálogo entre microeconomistas e macroeconomistas sobre empreendedorismo. Segundo, por mostrar que a queda de empreendedores ao mesmo tempo em que se observa o aumento de crédito na economia é um acontecimento plenamente possível quando se tem em mente um efeito de equilíbrio geral. Terceiro, por evidenciar que a diminuição da restrição de crédito possui um efeito heterogêneo nos agentes quando se estratifica pela riqueza.

O trabalho está organizado da seguinte maneira. A Seção 2 apresenta o modelo e discute os resultados. A Seção 3 descreve algumas evidências dos dados brasileiros. A Seção 4 apresenta os exercícios numéricos. A Seção 5 conclui o trabalho.

\section{MODELO}

Nesta seção, apresentamos o modelo de empreendedorismo que se baseia em Evans e Jovanovic (1989). O modelo proposto busca explicar a escolha ocupacional como a interação entre restrição de crédito, riqueza inicial e talento empreendedor. Inicialmente, o modelo possui apenas duas ocupações, em que os indivíduos podem abrir um negócio ou trabalhar por um salário, adicionando uma condição de equilíbrio geral no mercado de trabalho. Com apenas essas modificação em relação ao modelo EJ, discutimos a estática comparativa e os principais resultados. $\mathrm{Na}$ última subseção, enriquecemos o modelo ao adicionar outra ocupação, a atividade conta-própria.

\subsection{Preferências e tecnologia}

O modelo é estático. A economia é composta por um contínuo de indivíduos heterogêneos exante em duas dimensões: talento empreendedor $\theta \in[0,+\infty)$ e dotação de riqueza $A \in$ $[0,+\infty)$. Essas variáveis estão distribuídas de acordo com a função densidade $\Gamma(\theta, A)$.

Os agentes dessa economia escolhem entre abrir uma firma ou trabalhar para um empreendedor. Empreendedores recebem os lucros, enquanto trabalhadores recebem o salário de mercado. Agentes escolhem suas ocupações de maneira a maximizar seus ganhos, sendo 
indiferentes quanto ao uso do seu tempo. Em adição ao talento e à riqueza, todos os agentes são dotados de uma unidade de trabalho, que é ofertada inelasticamente.

A tecnologia operada por um empreendedor é descrita por $\theta[f(k, l)]^{\gamma}$, em que $k$ representa o capital utilizado e $l$ representa o montante de trabalho, e $\gamma \in(0,1)$. Supomos que a função $f$ é homogênea de grau $1, f_{k}(k, l)>0, f_{l}(k, l)>0, f_{k k}(k, l)<0, f_{l l}(k, l)<0$. Com essas hipóteses, o Teorema de Euler nos garante que $f_{k l}(k, l)>0$. Ainda, suponha condições de Inada: $\lim _{k \rightarrow \infty} f_{k}(k, l)=0, \lim _{k \rightarrow 0} f_{k}(k, l)=\infty, \lim _{l \rightarrow \infty} f_{l}(k, l)=0, \lim _{l \rightarrow 0} f_{l}(k, l)=\infty$, $f(k, 0)=0$ e $f(0, n)=0$.

Como em Lucas (1978), a tecnologia depende diretamente do talento: um empreendedor mais talentoso tem tanto um produto como um produto marginal maior. $\mathrm{O}$ parâmetro $\gamma$ representa o efeito "span-of-control": a produção possui retornos decrescentes de escala em relação ao talento empreendedor.

\subsection{Mercados}

O mercado de trabalho é competitivo, isto é, o salário se ajusta para igualar oferta de trabalho com a demanda de trabalho por parte dos empreendedores ${ }^{5}$. Diferentemente, o mercado de crédito é caracterizado por uma restrição de crédito. Para modelar a restrição de crédito, adotamos uma imperfeição do tipo comprometimento limitado, como em Banerjee e Newman (1993) e Ghatak e Jiang (2002). Tal imperfeição se origina da hipótese de que os contratos são imperfeitamente executáveis ${ }^{6}$ (imperfectly enforceable), o que significa que o emprestador não tem poder suficiente para obrigar o devedor a pagar suas dívidas, sendo que o devedor somente cumpre o contrato se for de seu próprio interesse. Como forma de aumentar os incentivos para o cumprimento do contrato, o emprestador exige que o tomador deixe toda a sua riqueza como colateral. Como conseqüência, pessoas mais ricas têm maior acesso a crédito.

\footnotetext{
${ }^{5} \mathrm{O}$ equilíbrio no mercado de capital não é levado em conta no modelo. Temos em mente uma pequena economia aberta, em que a taxa de juros é determinada exogenamente.

${ }^{6}$ Restrições de crédito originadas do problema de moral hazard são tratadas por Aghion e Bolton (1997). Paulson, Townsend e Karaivanov (2006) propõem um modelo que permite os dois tipos de imperfeições no mercado de crédito.
} 
Supomos que os agentes são neutros a risco. A única razão nessa economia para tomar emprestado é com o objetivo de abrir um negócio. O empreendedor pode pagar ou pode renegar sua dívida. Caso pague, seu payoff será

$$
\theta[f(k, l)]^{\gamma}-w l-r(k-A)
$$

em que $w$ é o salário e $r$ é a taxa de juros bruta. Em caso de optar por renegar o contrato, o empreendedor pode ser detido com uma probabilidade $\pi$ ou pode escapar com probabilidade $(1-\pi)$. Caso seja pego, o empreendedor sofre uma punição por ter tentado evadir, de forma que apenas uma parte de sua riqueza, $0 \leq \phi<1$, deixada como colateral, é devolvida pelo emprestador. Caso escape, o empreendedor não paga o montante de crédito adquirido, mas também não recebe o colateral. Não há possibilidade de default sobre a mão-de-obra contratada. Dessa forma, o payoff de renegar o contrato é

$$
\pi\left[\theta[f(k, l)]^{\gamma}-w l-r(k-\phi A)\right]+(1-\pi)\left[\theta[f(k, l)]^{\gamma}-w l\right]
$$

Os emprestadores apenas propõem um contrato e um montante de empréstimo que seja do interesse do devedor pagar. Assim, os contratos existentes são aqueles que respeitam a restrição de compatibilidade de incentivos

$$
\begin{aligned}
& \theta[f(k, l)]^{\gamma}-w l-r(k-A) \\
& \geq \pi\left[\theta[f(k, l)]^{\gamma}-w l-r(k-\phi A)\right]+(1-\pi)\left[\theta[f(k, l)]^{\gamma}-w l\right]
\end{aligned}
$$

resultando em um contrato de débito simples colaterizado

$$
k \leq \lambda A
$$

em que $\lambda=\left(\frac{1-\pi \phi}{1-\pi}\right) \geq 1$. A intuição para a equação (1) é que, quanto mais rico for o empreendedor, maior sua perda no caso de calote e maior seu incentivo para cumprir o contrato. Sabendo disso, maior é o montante que o credor se dispõe a emprestar ${ }^{7}$. Interessante notar que $\lim _{\pi \rightarrow 0} \lambda=1, \lim _{\pi \rightarrow 1} \lambda=+\infty, \lim _{\phi \rightarrow 0} \lambda=\frac{1}{1-\pi}, \lim _{\phi \rightarrow 1} \lambda=1$. Quanto mais efetivo

\footnotetext{
${ }^{7}$ Kehoe e Levine (1993) apresentam um tratamento bastante completo da determinação endógena da restrição de crédito.
} 
for o enforcement, representado por $\pi \rightarrow 1 e \phi \rightarrow 0$, maior é o montante de crédito disponível.

\subsection{Ocupações}

Existem duas ocupações no modelo:

(i) Trabalhador: Um indivíduo trabalha para um empreendedor e recebe um salário (determinado endogenamente). Sua dotação de riqueza é investida num ativo livre de risco, que tem taxa de juros bruta $r$. Seu ganho é $w+r A$.

(ii) Empreendedor: Um indivíduo investe o montante $k$ de capital e contrata $l$ de trabalho, utilizando a tecnologia $\theta[f(k, l)]^{\gamma}$. O ganho do empreendedor é $V_{E}+r A$, em que $V_{E}$ é o lucro da firma dado por

$$
\max _{k, l} \theta[f(k, l)]^{\gamma}-w l-r k
$$

Pelo Teorema da Função Implícita, temos que o capital ótimo $k^{*}(\theta)$ e o trabalho ótimo $l^{*}(\theta)$ são funções positivas do talento: quanto maior o talento, maior é a produtividade marginal dos fatores e maior é a quantidade demandada. No entanto, devido à existência de restrições financeiras, o capital utilizado é

$$
k^{u}=\min \left\{k^{*}(\theta), \lambda A\right\}
$$

Dizemos que o indivíduo é irrestrito quando $k^{u}=k^{*}(\theta)$, ou seja, $k^{*}(\theta) \leq \lambda A$ e restrito quando $k^{u}=\lambda A$, ou seja, $k^{*}(\theta)>\lambda A$. Caso seja restrito, o lucro do empreendedor é

$$
\max _{l} \theta[f(\lambda A, l)]^{\gamma}-w l-r \lambda A
$$

em que, a escolha ótima de trabalho agora é função do nível de riqueza, $l^{* *}(\theta, A)$. Note que, caso os empreendedores sejam irrestritos, como ocorre numa situação de ausência de imperfeições, os níveis ótimos de capital e trabalho são apenas funções dos parâmetros de 
tecnologia e do talento empreendedor. Todavia, indivíduos restritos a crédito não conseguem investir o montante de capital desejado, implicando nas escolhas ótimas como funções do nível de riqueza. Dessa forma, o lucro do empreendedor irrestrito é $V_{E}=V_{U E}(\theta)$ e o lucro do empreendedor restrito é $V_{E}=V_{C E}(\theta, A)$. Pelo Teorema do Envelope, $\frac{\partial V_{U E}}{\partial \theta}>0, \frac{\partial V_{C E}}{\partial \theta}>0$, $\frac{\partial V_{C E}}{\partial A}>0$

\subsection{Equação de seleção}

Por conveniência exposicional, tome o salário como dado ${ }^{8}$. Supomos que o indivíduo conhece seu talento empreendedor antes da decisão ocupacional ${ }^{9}$. Os agentes escolhem suas ocupações de maneira a maximizar seus ganhos, sendo indiferentes quanto ao uso do seu tempo. A condição de seleção para empreendedorismo é dada por

$$
V_{E}+r A \geq w+r A
$$

Como os empreendedores renunciam seus ganhos como trabalhadores, um indivíduo apenas escolhe abrir um negócio se consegue investir o suficiente, isto é, se ele for rico o bastante para pedir emprestado um montante adequado. Essa correlação positiva entre empreendedorismo e riqueza pode vista pela equação (3).

Assim, devemos caracterizar os indivíduos entre restritos e irrestritos, caso decidam abrir um negócio. Depois, calculamos as equações de seleção separadamente para cada caso. Dessa forma, podemos criar uma regra que caracteriza completamente as decisões dos indivíduos no espaço talento-riqueza. Para isso, primeiro, caracterizamos os seguintes limiares.

Lema 1: Os seguintes limiares existem no espaço talento-riqueza:

(i) Existe um nível de talento, $\theta_{u}$, que não depende do nível de riqueza, tal que $V_{U E}\left(\theta_{u}\right)=w$.

(ii) Para $A \leq A^{*}$, em que $A^{*}=\frac{k^{*}\left(\theta_{u}\right)}{\lambda}$, existe um nível de talento, $\theta_{c}(A)$, decrescente na riqueza, tal que $V_{C E}\left(\theta_{c}(A), A\right)=w$.

\footnotetext{
${ }^{8}$ A subseção 2.5 trata da determinação do equilíbrio no mercado de trabalho.

${ }^{9} \mathrm{Um}$ modelo em que os agentes são imperfeitamente informados sobre o talento é apresentado por Taveras (2009).
} 
(iii) Para $\forall A$, existe um nível de talento, $\theta_{b}(A)$, crescente na riqueza, tal que $k^{*}\left(\theta_{b}(A)\right)=$ $\lambda A$.

(iv) Existe um nível de riqueza $A^{*}$ em que $\theta_{u}=\theta_{c}\left(A^{*}\right)=\theta_{b}\left(A^{*}\right)$.

Prova: (i) Tome os indivíduos $(\theta, A)$ indiferentes entre ser empreendedor irrestrito $\mathrm{e}$ trabalhador. Para esses, $V_{U E}(\theta)=w$. Pelo fato de $\theta \in[0,+\infty), \exists \theta=\theta_{u}$ que iguala esses ganhos, de forma que esses indivíduos são $\left(\theta_{u}, A\right)$. Note que $\theta_{u}$ não é função da riqueza. Esse limiar é equivalente ao limiar em um modelo de mercados perfeitos, em que $\theta \geq \theta_{u}$ implica em empreendedorismo e, caso contrário, $\theta<\theta_{u}$, implica em trabalho assalariado.

(ii) Para os indivíduos com $\theta=\theta_{u}$, tome aquele que tem $A^{*}=\frac{k^{*}\left(\theta_{u}\right)}{\lambda}$. Esse indivíduo $\left(A^{*}, \theta_{u}\right)$ está no limite entre ser empreendedor ou trabalhador e, mais que isso, seu nível ótimo de capital é exatamente igual ao máximo permitido, se situando também no limite entre restrito e irrestrito. Tome um indivíduo $\left(A_{1}, \theta_{u}\right), A_{1}<A^{*}$. Esse indivíduo é restrito. Ele possui um lucro menor que o de $\left(A^{*}, \theta_{u}\right)$, uma vez que investe $\lambda A_{1}$, ao invés de $k^{*}\left(\theta_{u}\right)$. Se $\left(A^{*}, \theta_{u}\right)$ está indiferente entre trabalhador e empreendedor, com certeza $\left(A_{1}, \theta_{u}\right)$ opta por ser trabalhador. Conforme indivíduos ficam mais pobres, para serem indiferentes entre empreendedor restrito e trabalhador, ou seja, $V_{C E}\left(\theta_{c}(A), A\right)=w$, devem ter talento cada vez maior. Dessa forma, para região $A<A^{*}$, caracterizamos uma curva $\theta_{c}(A)$, decrescente na riqueza,. Indivíduos com $\theta<\theta_{c}(A)$ optam pelo trabalho assalariado e, caso contrário, $\theta \geq \theta_{c}(A)$, optam pelo empreendedorismo.

(iii) Indivíduos no limite da restrição de crédito são aqueles que, $k^{*}(\theta)=\lambda A$, o que gera o limiar $\theta_{b}(A)=k^{*-1}(\lambda A)$. Essa curva é crescente na riqueza: quanto maior o talento, maior o investimento desejado e maior deve ser a riqueza que o leva ao limite de ser restrito. Empreendedores restritos tem $\theta>\theta_{b}(A)$ e, irrestritos, $\theta \leq \theta_{b}(A)$.

(iv) Conforme os argumentos acima, o nível de riqueza $A^{*}$ é o ponto em que as três curvas se cruzam.

As curvas $\theta_{u}$ e $\theta_{c}(A)$ representam limiares entre empreendedores e trabalhadores. A curva $\theta_{b}(A)$ representa o limiar entre restrito ou irrestrito. Com o Lema 1 , as ocupações podem ser caracterizadas no espaço talento-riqueza conforme a seguinte proposição 
Proposição 1: As seguintes regras particionam o espaço talento-riqueza entre as ocupações:

(i) Empreendedor Irrestrito: $\theta_{u} \leq \theta \leq \theta_{b}(A)$

(ii) Empreendedor Restrito: $\theta>\max \left\{\theta_{c}(A), \theta_{b}(A)\right\}$

(iii) Trabalhador: caso contrário

Prova: Decorrência direta do Lema 1.

A relação entre riqueza, talento e escolha ocupacional que surge do modelo pode ser vista na figura $10^{10}$, particionando o espaço talento-riqueza em cinco áreas: (1) uma área de empreendedores irrestritos $U E$ [aqueles que possuem riqueza maior que $A^{*}$ e talento alto suficiente para compensar as perdas de ser trabalhador, mas não tão alto para implicar restrição de crédito], (2) uma área de empreendedores restritos, representados pela região $C E 1$ [aqueles que possuem riqueza menor que $A^{*}$, mas talento suficientemente alto para abrir um negócio, apesar de serem restritos a crédito], (3) outra área de empreendedores restritos, representados pela região CE2 [aqueles que, apesar de possuírem riqueza maior que $A^{*}$, têm talento mais alto ainda proporcionalmente, o que implica em restrição à crédito]. (4) uma área de trabalhadores, representados pela região $W W 1$ [trabalhadores nessa região, caso mercado de crédito fosse perfeito, optariam pelo empreendedorismo; sob mercados perfeitos, apenas o único limiar existente seria $\theta_{u}$ ], (5) outra área de trabalhadores, representados pela região $W W 2$ [indivíduos optariam pelo trabalho assalariado mesmo sob mercados perfeitos].

Neste gráfico, podemos ver claramente como o modelo contempla a existência de uma correlação positiva entre riqueza e empreendedorismo: na região $A<A^{*}$, conforme a riqueza aumenta, maior massa de indivíduos se torna empreendedores. A partir de $A \geq A^{*}$, a única restrição de crédito se dá na margem intensiva, ou seja, indivíduos restritos desejariam investir mais.

\footnotetext{
${ }^{10}$ A Figura 1 foi feita com a função de produção $f(k, l)=k^{\alpha} l^{1-\alpha}$ e com os valores: $\alpha=0,3, \gamma=0,85, \lambda=$ $1,0, r=1,20$, e $w=4,32$.
} 


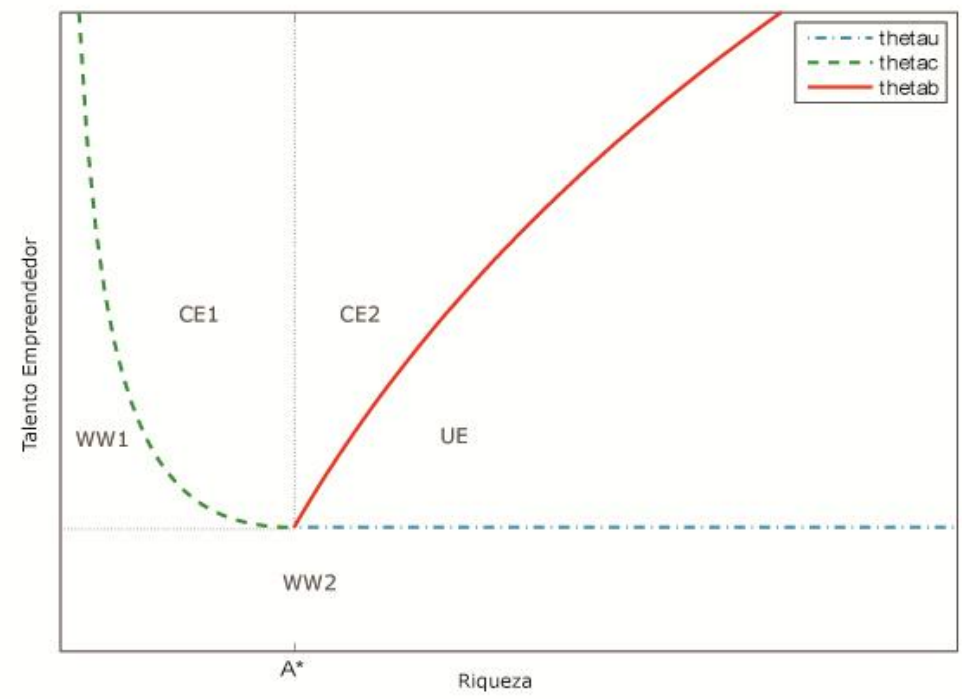

Figura 1: Distribuição de ocupações no espaço talento-riqueza

\subsection{Equilíbrio}

Até agora tomamos a condição de seleção como função de um salário dado. No entanto, o modelo aqui proposto impõe que o mercado de trabalho deve se equilibrar de tal forma que a oferta de trabalho se iguale à demanda de trabalho por parte dos empreendedores. Daí resulta um salário de equilíbrio.

Defina as seguintes funções indicadoras

$$
\begin{gathered}
s(\theta, A, w)=\left\{\begin{array}{l}
1, \text { se individuo é empreendedor } \\
0, \text { se individuo é trabalhador }
\end{array}\right. \\
m(\theta, A, w)=\left\{\begin{array}{l}
1, \text { se empreendedor é restrito } \\
0, \text { se empreendedor é irrestrito }
\end{array}\right.
\end{gathered}
$$

Definição: Um equilíbrio nessa economia se constitui em um vetor $\{s(\theta, A, w), m(\theta, A, w), l(\theta, A, w), w\}, \forall(\theta, A)$ tal que:

(i) dado o salário de equilíbrio, empreendedores demandam capital e trabalho de forma a maximizar lucro

(ii) indivíduos escolhem suas ocupações de forma a maximizar seus ganhos

(iii) o mercado de trabalho se equilibra: 


$$
\begin{aligned}
\int_{0}^{+\infty} \int_{0}^{+\infty} s(\theta, A & \left., w^{*}\right) m\left(\theta, A, w^{*}\right) l^{* *}\left(\theta, A, w^{*}\right) \Gamma(\theta, A) d \theta d A \\
& +\int_{0}^{+\infty} \int_{0}^{+\infty} s\left(\theta, A, w^{*}\right)\left[1-m\left(\theta, A, w^{*}\right)\right] l^{*}\left(\theta, w^{*}\right) \Gamma(\theta, A) d \theta d A \\
& =\int_{0}^{+\infty} \int_{0}^{+\infty}\left[1-s\left(\theta, A, w^{*}\right)\right] \Gamma(\theta, A) d \theta d A
\end{aligned}
$$

em que o primeiro termo do lado esquerdo representa a demanda por trabalho dos empreendedores restritos e o segundo termo é a demanda por trabalho dos empreendedores irrestritos. O lado direito representa a oferta de trabalho. Para garantir a existência de equilíbrio, necessitamos da seguinte hipótese:

Hipótese: Para $\forall w$, temos que

$$
\lim _{\theta \rightarrow+\infty} \int_{0}^{+\infty} \int_{\theta}^{+\infty} l^{*}(\theta, w) \Gamma(\theta, A) d \theta d A=0
$$

Essa hipótese implica que conforme o talento aumenta, indivíduos mais talentosos, apesar de demandar maior quantidade de trabalho, ficam cada vez mais raros, de forma que não existe massa de empreendedores que demandam uma quantidade infinita de trabalho. Isso é verdade quando o suporte de talento ou quando a função demanda de trabalho são conjuntos limitados. Com a Hipótese 1 e pressupostos do modelo, temos que

Proposição 2: Existe um salário $w^{*}$ que equilibra o mercado de trabalho.

A prova dessa proposição se encontra no Apêndice A. Intuitivamente, mostramos que existe um nível de salário suficientemente baixo tal que existe excesso de demanda. De modo análogo, existe um nível de salário suficientemente alto tal que existe excesso de oferta de trabalho. Pela continuidade da demanda agregada excedente, garantimos a existência de um salário que equilibra o mercado de trabalho. 


\subsection{Estática comparativa}

Esta seção estuda como um aumento do parâmetro de comprometimento limitado $\lambda$ se reflete sobre a distribuição de ocupações em equilíbrio. Nesse exercício de estática comparativa, mostramos que a diminuição da restrição de crédito: i) diminui a proporção de empreendedores entre indivíduos suficientemente ricos e, ii) tem efeito indeterminado sobre a proporção de empreendedores entre indivíduos suficientemente pobres.

Primeiro, para entender o comportamento dos indivíduos, devemos analisar qual é o efeito da diminuição da restrição de crédito sobre os ganhos das ocupações. Esse é o objetivo dos seguintes lemas.

Lema 2: Tome um salário de equilíbrio $w^{*}$. Um aumento de $\lambda$ aumenta o salário de equilíbrio,

$$
\frac{\partial w^{*}}{\partial \lambda}>0
$$

Prova: Tome $\lambda^{\prime}>\lambda$. Por contradição, suponha que $\frac{\partial w^{*}}{\partial \lambda}<0$. Devemos considerar indivíduos em quatro regiões:

(i) $\theta_{u} \leq \theta<\theta_{c}(A)$, para $A<A^{*}$

Correspondem aos indivíduos na região $W W 1$. Um aumento de $\lambda$ faz com que $V_{C E}\left(\lambda^{\prime}\right) \geq$ $w^{*}\left(\lambda^{\prime}\right)$ para alguns indivíduos trabalhadores. Esses indivíduos deixam de ofertar trabalho e decidem demandar trabalho.

(ii) $\theta \geq \max \left\{\theta_{b}(A), \theta_{c}(A)\right\}$

Correspondem aos indivíduos nas regiões $C E 1$ e $C E 2$. Empreendedores restritos demandam mais capital. Ainda, para indivíduos nessa região, o aumento de $\lambda$ leva a alguns empreendedores anteriormente restritos a demandar exatamente $k^{*}(\theta)$. Por $f_{k l}>0$, ocorre aumento da demanda de trabalho.

(iii) $\theta_{u}<\theta<\theta_{b}(A)$, para $A>A^{*}$

Correspondem aos indivíduos na região $U E$. Todos empreendedores nessa região investem exatamente $k^{*}(\theta)$. Empreendedores não mudam comportamento com o aumento de lambda. 
(iv) $\theta<\theta_{u}$, para $\forall A$

Correspondem aos indivíduos na região $W W 2$. Esses indivíduos, por ter baixo talento, não optam pelo empreendedorismo mesmo com o aumento de $\lambda$.

Vemos que, nesses quatro casos, o aumento de $\lambda$ para $\lambda^{\prime}$ acompanhado por $\frac{\partial w^{*}}{\partial \lambda}<0$ leva a um aumento da demanda de trabalho com queda da oferta, contrariando a hipótese de equilíbrio. Para equilibrar o mercado, $\frac{\partial w^{*}}{\partial \lambda}>0$.

\section{Lema 3:}

(i) Um aumento de $\lambda$ diminui o lucro dos empreendedores irrestritos, $\frac{\partial V_{U E}}{\partial \lambda}<0$.

(ii) Um aumento de $\lambda$ aumenta o lucro dos empreendedores restritos suficientemente pobres, $\lim _{A \rightarrow 0} \frac{\partial V_{C E}\left(\theta_{c}\right)}{\partial \lambda}>0$.

Prova: (i) Para os empreendedores irrestritos, temos que, pelo Teorema do Envelope

$$
\frac{\partial V_{U E}}{\partial \lambda}=-\frac{\partial w^{*}}{\partial \lambda} l^{*}<0
$$

(ii) Para os empreendedores restritos, temos que, pelo Teorema do Envelope

$$
\frac{\partial V_{C E}}{\partial \lambda}=\left\{\theta \gamma\left[f\left(\lambda A, l^{* *}\right)\right]^{\gamma-1} f_{k}\left(\lambda A, l^{* *}\right)-r\right\} A-\frac{\partial w^{*}}{\partial \lambda} l^{* *}
$$

O termo em chaves é positivo, uma vez que indivíduos restritos não igualam a produtividade marginal à taxa de juros. Dessa forma, não podemos comparar a magnitude desse efeito com o custo de contratação de trabalho que é gerado pelo aumento do salário de equilíbrio. Todavia, o sentido desse efeito para empreendedores restritos é determinado apenas para indivíduos suficientemente pobres.

Tome os indivíduos que estão no limiar entre empreendedor restrito e trabalhador, ou seja, aqueles que têm $\theta_{c}=\frac{w^{*}+w^{*} l^{* *}+r \lambda A}{\left[f\left(\lambda A, l^{* *}\right)\right]^{\gamma}}$ e $A<A^{*}$. Substituindo em (7), temos que 


$$
\frac{\partial V_{C E}\left(\theta_{c}\right)}{\partial \lambda}=\frac{\gamma}{\lambda} \frac{\lambda A f_{k}\left(\lambda A, l^{* *}\right)}{f\left(\lambda A, l^{* *}\right)}\left[r \lambda A+w^{*}+w^{*} l^{* *}\right]-\frac{\partial w^{*}}{\partial \lambda} l^{* *}-r A
$$

e, conforme $A \rightarrow 0$,

$$
\lim _{A \rightarrow 0} \frac{\partial V_{C E}\left(\theta_{c}\right)}{\partial \lambda}>0
$$

Isso é garantido pelo termo

$$
\frac{k f_{k}(k, l)}{f(k, l)}=\frac{k f_{k}(k, l)}{k f_{k}(k, l)+l f_{l}(k, l)} \in(0,1)
$$

Dessa forma, uma queda da restrição de crédito é acompanhada por um aumento do salário de equilíbrio, aumentando o ganho de trabalhadores e diminuindo o ganho de empreendedores irrestritos. Todavia, o efeito é indeterminado sobre empreendedores restritos. Isso faz sentido, uma vez que empreendedores irrestritos não mudam o nível ótimo de capital com a menor restrição de crédito, porém, o aumento do salário que advém do efeito de equilíbrio geral, diminui o lucro. Diferentemente, para empreendedores restritos, apesar de maior acesso a crédito, ocorre também aumento do custo de mão-de-obra, implicando em um efeito indeterminado sobre os ganhos. Apenas indivíduos suficientemente pobres têm maior lucro como empreendedores restritos. De posse desses lemas sobre os efeitos dos ganhos das ocupações, a próxima proposição nos diz o efeito da queda de restrição sobre as ocupações em equilíbrio.

\section{Proposição 3:}

(i) Um aumento de $\lambda$ diminui a proporção de empreendedores suficientemente ricos.

(ii) Um aumento de $\lambda$ tem efeito indeterminado sobre a proporção de empreendedores suficientemente pobres.

Prova: (i) Tome indivíduos que estão no limiar entre empreendedor irrestrito e trabalhador, ou seja, $\theta=\theta_{u}$ e $A>A^{*}$. Com o aumento de $\lambda, w^{*}$ aumenta e $V_{U E}$ diminui, levando indivíduos a optarem pelo trabalho assalariado. 
(ii) Tome os indivíduos com $\theta=\theta_{c}$ e $A \rightarrow 0$. O ganho de empreendedorismo aumenta. Porém, mesmo para esses indivíduos, temos uma indeterminação com respeito à decisão ocupacional, uma vez que não podemos comparar a magnitude desse efeito com o aumento de salário. Obviamente, também temos uma indeterminação para empreendedores restritos com $0<A<A^{*}$.

Essa proposição afirma que o afrouxamento de crédito com certeza diminui empreendedorismo para a fração mais rica, porém tem efeito indeterminado sobre a fração mais pobre. Simulações numéricas apresentadas na Seção 4 mostram que, para as formas funcionais e distribuições adotadas, uma fração de indivíduos pobres optam pelo empreendedorismo, apesar do aumento de salário. O efeito final sobre empreendedorismo depende fundamentalmente da distribuição de riqueza na população. Por exemplo, empreendedorismo diminui caso exista massa suficiente de indivíduos com riqueza acima de certo nível.

Em adição à correlação positiva entre empreendedorismo e riqueza, esse resultado garante que o modelo proposto contempla uma correlação negativa entre empreendedorismo e acumulação de capital, efeito não presente no modelo EJ. Note que esse resultado advém diretamente da condição de equilíbrio geral no mercado de trabalho.

\subsection{Extensão com conta-própria}

Essa subseção tem como objetivo introduzir a atividade conta-própria como outra ocupação no modelo. Essa extensão deve por dois motivos. Primeiro, pelo fato de uma fração relevante dos indivíduos optarem por essa atividade. Segundo, por muitos trabalhos tratarem empreendedorismo e conta-própria como atividades semelhantes, o que certamente não é o caso para países em desenvolvimento.

De fato, não existe um consenso acerca de uma definição precisa do termo empreendedorismo. Por exemplo, Evans e Jovanovic (1989) e Blanchflower e Oswald (1998) definem empreendedores como agentes conta própria, enquanto que Hurst e Lusardi (2004) e Cagetti e Denardi (2006) focam em proprietários de negócios (empregadores). Essa distinção 
não apresenta diferença substancial para os Estados Unidos, como aponta Hurst e Lusardi (2004).

Todavia, em países em desenvolvimento, agentes conta-própria são bastante diferentes de indivíduos empregadores. A atividade conta-própria é geralmente associada à pobreza, sendo considerada uma forma disfarçada de desemprego. Mondragón-Vélez e Peña-Parga (2008) encontram, para o caso colombiano, que a atividade conta-própria está relacionada a uma forma de subsistência, diferindo em importantes dimensões de indivíduos empregadores: indivíduos conta-própria possuem menor renda, menor riqueza, menor número de anos de educação e estão mais ligados ao trabalho informal.

Ainda, no modelo apresentado, crédito tomado por empreendedores é necessário para uso de capital na produção. Certos tipos de agentes conta-própria que vemos nos dados não se enquadram nessa classificação: por exemplo, "flanelinhas", diaristas e engraxates são profissões que necessitam pouco ou nenhum investimento e qualquer alteração no mercado de crédito não deve gerar mudanças significativas no comportamento desses indivíduos.

Esses argumentos nos levaram a propor uma extensão do modelo. Diferentemente do agente conta-própria caracterizado em Banerjee e Newman (1993) e Gollin (2008), que necessita de capital para produção, supomos que essa atividade é idêntica à ocupação de subsistência presente em Ghatak e Jiang (2002). Supomos que existe uma tecnologia de subsistência que não usa capital e usa 1 unidade de trabalho para produzir $\mu$ unidades de produto. $\mathrm{O}$ ganho dessa atividade é dado por

$$
\mu+r A
$$

em que $\mu>0$. Além da ocupação de conta-própria, adicionamos uma nova heterogeneidade $\xi \in[0,1]$, em que $\xi$ é a habilidade de trabalho. Os indivíduos são caracterizados pela função densidade $\Gamma(\theta, A, \xi)$.

Modificações são feitas nos ganhos das outras ocupações. O ganho de trabalhador é dado por

$$
e^{\operatorname{clog}(A)} \xi w+r A
$$


e o ganho de empreendedor é

$$
\max _{k, l} e^{\operatorname{clog}(A)} \theta[f(k, l)]^{\gamma}-w l-r(k-A)
$$

em que $c \in(0,1)$. Intuitivamente, trabalhadores, ao invés de ofertar uma unidade de trabalho, agora ofertam $e^{\operatorname{clog}(A)} \xi$ unidades de trabalho, que equivalem a 1 unidade de trabalhoeficiência. Para empreendedorismo, indivíduos mais ricos agora têm maior produto por dois canais. Como anteriormente, ele teria maior lucro, pois tem maior acesso a crédito. Agora, um indivíduo mais rico também tem um produto maior. O termo $e^{\operatorname{clog}(A)}$ representa uma forma reduzida para ganhos de capital humano: indivíduos mais ricos têm maior acesso à educação, aumentando o capital humano e a produtividade tanto para trabalhar como para abrir um negócio. Essa adição é incluída com o objetivo de replicar os perfis não-paramétricos entre as ocupações e riqueza, conforme apresentados na subseção 3.1

Podemos entender o rendimento $\mu$ como um salário de reserva. Caso o rendimento do trabalho assalariado seja menor que esse valor, todo potencial trabalhador adota a tecnologia de subsistência. De forma oposta, caso $\mu$ seja menor que o rendimento de trabalho, ninguém opta pela atividade conta-própria. É por esse motivo que adicionamos outra fonte de heterogeneidade, a habilidade de trabalho, e conectamos os ganhos de trabalho assalariado e empreendedorismo à riqueza. Dessa forma, caracterizamos a ocupação conta-própria como uma atividade ligada à pobreza e, independentemente dos valores de parâmetros, garantimos que sempre existe uma fração de agentes que opta pela atividade conta-própria, sejam aqueles pobres ou poucos talentosos.

Indivíduos escolhem as ocupações de forma a maximizar os ganhos. Defina as seguintes funções indicadoras

$$
\begin{gathered}
s(\theta, A, \xi, w)=\left\{\begin{array}{c}
1, \text { se individuo é empreendedor } \\
0, \text { caso contrário }
\end{array}\right. \\
m(\theta, A, \xi, w)=\left\{\begin{array}{c}
1, \text { se empreendedor é restrito } \\
0, \text { se empreendedor é irrestrito }
\end{array}\right. \\
d(\theta, A, \xi, w)=\left\{\begin{array}{c}
1, \text { se individuo é trabalhador } \\
0, \text { caso contrário }
\end{array}\right.
\end{gathered}
$$


Definição: Um equilíbrio nessa economia se constitui em um vetor $\{s(\theta, A, \xi, w), m(\theta, A, \xi, w), d(\theta, A, \xi, w), l(\theta, A, w), w\}, \forall(\theta, A)$ tal que:

(i) dado o salário de equilíbrio, empreendedores demandam capital e trabalho de forma a maximizar lucro

(ii) indivíduos escolhem suas ocupações de forma a maximizar seus ganhos

(iii) o mercado de trabalho se equilibra:

$$
\begin{gathered}
\int_{0}^{1} \int_{0}^{+\infty} \int_{0}^{+\infty} s\left(\theta, A, \xi, w^{*}\right) m\left(\theta, A, \xi, w^{*}\right)[1 \\
\left.-d\left(\theta, A, \xi, w^{*}\right)\right] l^{* *}\left(\theta, A, w^{*}\right) \Gamma(\theta, A, \xi) d \theta d A d \xi+ \\
\int_{0}^{1} \int_{0}^{+\infty} \int_{0}^{+\infty} s\left(\theta, A, \xi, w^{*}\right)[1 \\
\left.\quad-m\left(\theta, A, \xi, w^{*}\right)\right]\left[1-d\left(\theta, A, \xi, w^{*}\right)\right] l^{*}\left(\theta, w^{*}\right) \Gamma(\theta, A, \xi) d \theta d A d \xi \\
=\int_{0}^{1} \int_{0}^{+\infty} \int_{0}^{+\infty}\left[1-s\left(\theta, A, \xi, w^{*}\right)\right]\left[1-d\left(\theta, A, \xi, w^{*}\right)\right] \Gamma(\theta, A, \xi) d \theta d A d \xi
\end{gathered}
$$

Apesar da adição dessa nova ocupação, nenhuma alteração relevante nos resultados anteriores é gerada com essa adição. Além disso, conseguimos explicar algumas evidências empíricas que o modelo base não permite. A subseção 4.3 apresenta o modelo computado numericamente e seus resultados.

\section{ALGUMAS EVIDÊNCIAS EMPÍRICAS DOS DADOS BRASILEIROS}

Nesta seção, apresentamos brevemente algumas evidências dos dados brasileiros, ressaltando que esses fatos são consistentes com as predições do modelo. $\mathrm{O}$ estudo utiliza os dados da Pesquisa Nacional de Amostra por Domicílio (PNAD) referente ao período 1995-2008 ${ }^{11}$. São analisados apenas indivíduos com idade entre 18 e 80 anos e que são empregadores, contaprópria ou trabalhadores assalariados. ${ }^{12}$ A Tabela B1 do Apêndice B apresenta algumas características dessas ocupações. Indo de acordo com os resultados de Mondragón-Vélez e

\footnotetext{
${ }^{11}$ Com exceção do ano 2000 em que foi realizado o Censo.

12 São analisadas apenas as ocupações para as atividades não-agrícolas. O modelo domiciliar de produção agrícola com escolha ocupacional pode ser visto em Eswaran e Kotwal (1986).
} 
Peña-Parga (2008) para a Colômbia, a atividade conta-própria apresenta menor renda, riqueza e número de anos de educação.

Em especial, evidenciamos a relação entre riqueza e empreendedorismo, em que se nota que restrições financeiras têm um papel importante sobre a decisão de ser empreendedor para os dados brasileiros. Além disso, apresentamos os padrões ocupacionais e o montante de crédito ao longo desse período, enfatizando que, apesar de reformas institucionais visando o aumento de crédito, a proporção de empreendedores diminui.

\subsection{Restrição de crédito}

Uma evidência da restrição de crédito para os microdados brasileiros pode ser sugerida através de uma regressão não-paramétrica entre a probabilidade de empreendedorismo e riqueza. Todavia, a PNAD não contém uma medida de riqueza individual. Para tal, dados domiciliares e individuais foram utilizados na construção de uma proxy dessa variável, que leva em conta três componentes: rendimentos de ativos financeiros, renda de aluguel de outros imóveis e o valor estimado da casa em que reside. Esta foi baseada em Madeira $(2006)^{13}$ e sua construção detalhada se encontra no Apêndice C. A Figura 2 apresenta o histograma e o perfil não-paramétrico dessa medida ${ }^{14}$. O Apêndice D contém as estimações das densidades separadas por ano.

\footnotetext{
${ }^{13}$ Outra medida de riqueza pode ser construída através da metodologia de componente principal, como em Assunção e Alves (2007) e Jeong e Townsend (2008).

${ }^{14}$ Como essas estimações são sensíveis aos outliers, o percentil mais rico da amostra não foi considerado. A função kernel utilizada é a Epanechnikov. A escolha do bandwidth segue a sugestão de Silverman (1986). Todos esses critérios são utilizados nas regressões não-paramétricas a seguir.
} 


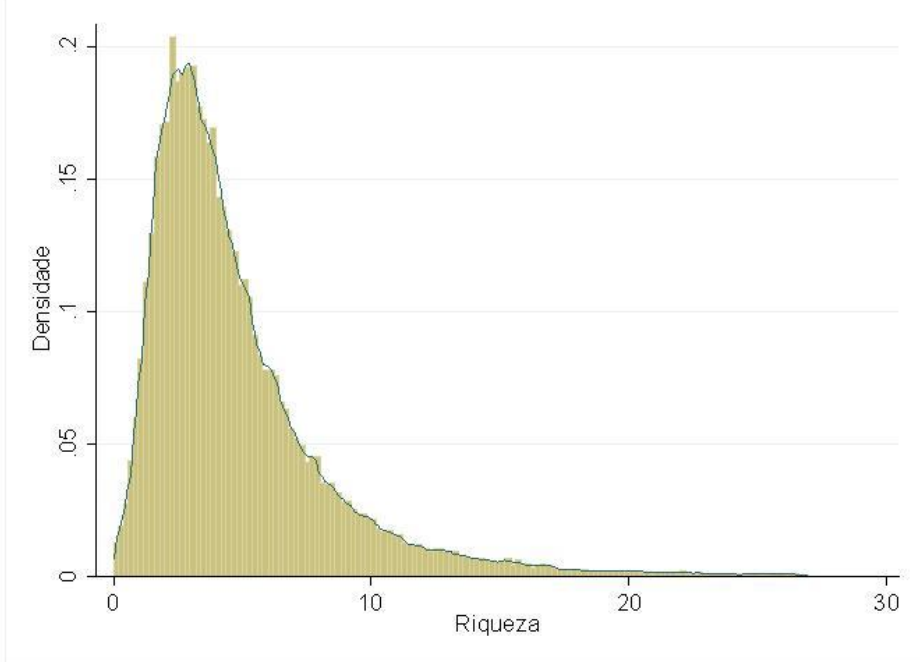

Figura 2: Estimação não-paramétrica da densidade de riqueza

Uma vez construída essa medida, a regressão não-paramétrica entre riqueza e empreendedorismo é apresentada na Figura 3. A região em cinza representa um intervalo de confiança de 95\%. Indo de encontro com as evidências para outros países, restrições financeiras também são encontradas nos dados brasileiros. Todavia, uma vez que estamos analisando as ocupações conjuntamente com a riqueza em um dado instante do tempo, talvez essa correlação positiva possa advir do fato de que riqueza ser uma conseqüência de empreendedorismo, ao invés de ser uma causa. Com o objetivo de mitigar esse problema, regressões não-paramétricas com apenas pessoas jovens (entre 18 e 29 anos) também são apresentadas. A evidência de uma correlação positiva se mantém ${ }^{15}$. As regressões para a amostra toda e para jovens feitas separadamente para cada ano se encontram no Apêndice D.

Regressões não-paramétricas feitas para agentes conta-própria e trabalhadores também são apresentadas na Figura 3. A relação negativa entre riqueza e conta-própria indica que, de fato, essa atividade está ligada à pobreza. O formato da regressão para trabalhadores tem o formato em parábola para baixo, indicando que para pessoas pobres, a probabilidade de ser trabalhador aumenta, porém, após certo nível de riqueza, pessoas mais ricas têm menor probabilidade de serem trabalhadoras. As mesmas evidências se mantém quando analisamos pessoas jovens. Esses perfis não-paramétricos serão explorados na seção de exercícios numéricos do modelo.

\footnotetext{
15 Ainda assim, a riqueza para pessoas jovens pode ser endógena. A determinação endógena entre riqueza e empreendedorismo é tratada por Buera (2008) e Buera (2009).
} 

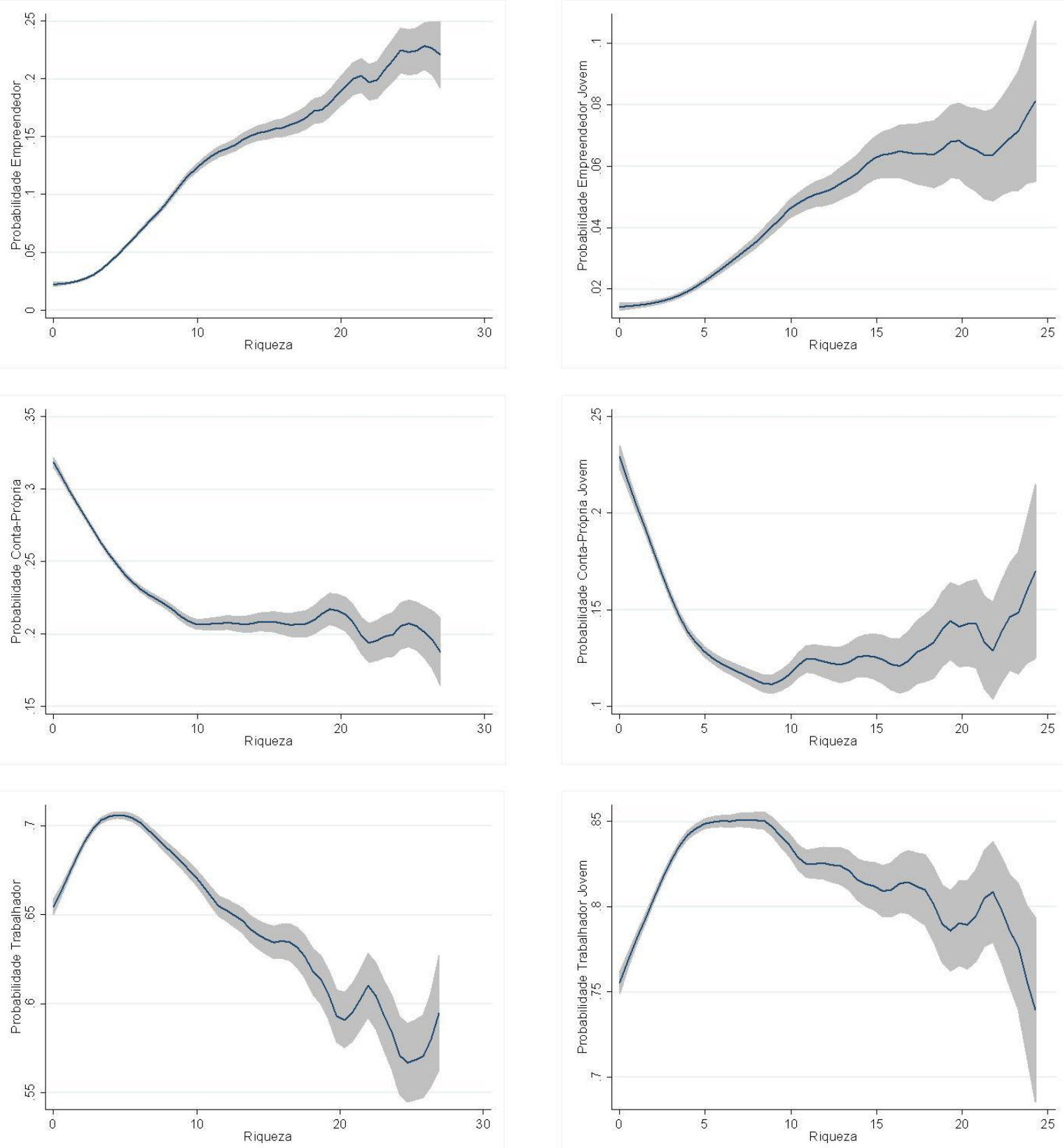

Figura 3: Regressão não-paramétrica entre as ocupações e riqueza

\subsection{Crédito e ocupações}

A Figura 4 apresenta o volume mensal das operações de crédito ao setor privado como proporção do PIB durante esse período. Nota-se uma expansão de crédito bastante acentuada após 2002. De fato, a partir de 2003, dentro de uma perspectiva decidida a viabilizar a expansão do crédito, algumas inovações na legislação são postas em andamento para 
fortalecer as garantias e segurança jurídica, estimular à concorrência e reduzir a cunha fiscal sobre a intermediação financeira. De fato, houve a expansão do microcrédito, do crédito consignado e de cooperativas de crédito e o advento da lei de falências, entre outras políticas. Cox, Coates e Calari (2006) e Araujo e Funchal (2010) apresentam uma discussão mais detalhada acerca das mudanças nas políticas de crédito ocorridas no Brasil para o período recente.

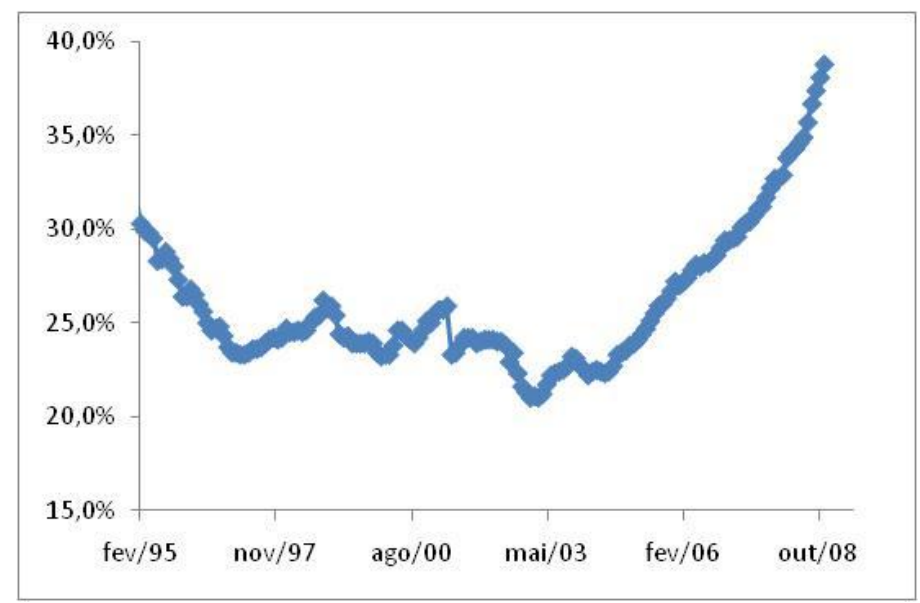

Figura 4: Operações de crédito ao setor privado como proporção do PIB para o período 1995-2008. Fonte: BACEN

Ao mesmo tempo em que se observa o aumento de crédito no Brasil, existe uma queda da proporção de empreendedores nos microdados, como apresentado na Figura 5a). As Figuras 5b) e 5c) apresentam as proporções de conta-própria e trabalhadores. Pode-se notar uma tendência de queda da proporção de empreendedores, queda da atividade conta-própria e aumento da proporção de trabalhadores.

Testa-se a significância estatística do comportamento dessas proporções ao longo do tempo de duas maneiras. Primeiro, regredimos a probabilidade da ocupação em uma constante, que representa a proporção da ocupação para o período 1995-2002 e em uma dummy $d 2$, que representa a variação da proporção para período 2003-2008, em que se tem maior disponibilidade de crédito. Os testes têm como objetivo verificar: i) se $d 2$ tem sinal negativo para empreendedorismo e conta-própria, e sinal positivo para trabalho assalariado; ii) se $d 2$ é estatisticamente diferente de zero. De maneira similar, regredimos a proporção da ocupação em uma tendência linear do tempo, verificando o sinal e significância estatística da tendência. As Tabelas 1 e 2 apresentam os resultados dessas regressões. Pelos dois modos, as quedas para empregadores e conta-própria e o aumento para trabalhadores são significativos a $1 \%$. 
a)

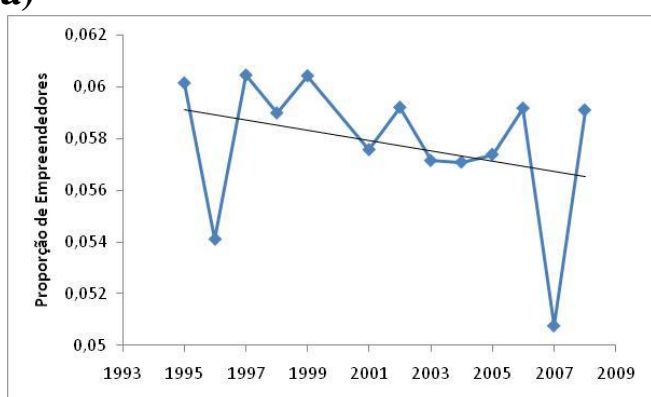

b)

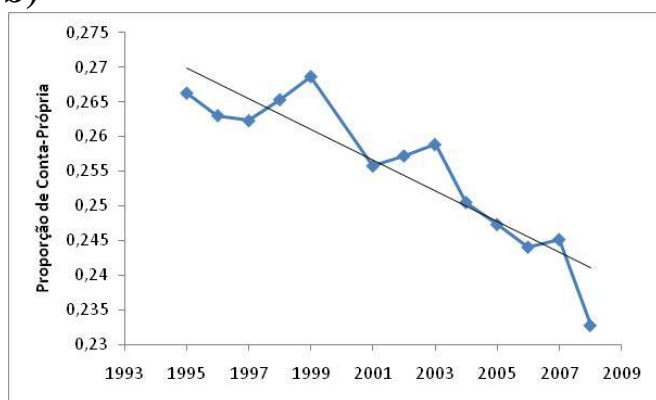

c)

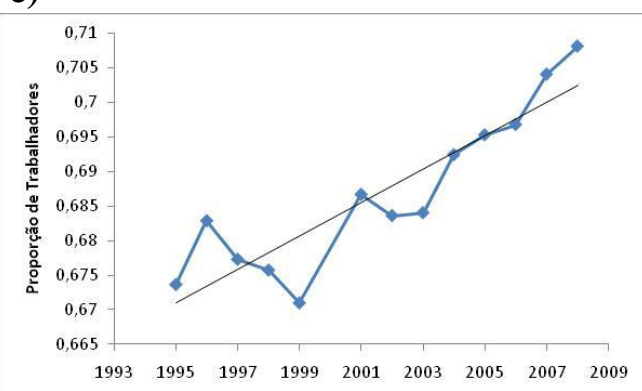

Figura 5: a) Proporção de Empreendedores, b) Proporção de Conta-Própria e c) Proporção de Trabalhadores para o período 1995-2008

Tabela 1: Regressão das ocupações em dummies

\begin{tabular}{|c|c|c|c|}
\hline & empreendedor & conta-própria & trabalhador \\
\hline d2 & $\begin{array}{c}-0.00194^{* * *} \\
(0.000482)\end{array}$ & $\begin{array}{l}-0.0162^{\star * \star} \\
(0.000900)\end{array}$ & $\begin{array}{c}0.0181^{* * *} \\
(0.000958)\end{array}$ \\
\hline const & $\begin{array}{c}0.0587^{* * *} \\
(0.000357)\end{array}$ & $\begin{array}{c}0.262^{* * *} \\
(0.000667)\end{array}$ & $\begin{array}{c}0.679^{* * *} \\
(0.000708)\end{array}$ \\
\hline
\end{tabular}

Tabela 2: Regressão das ocupações em uma tendência linear

\begin{tabular}{lccc}
\hline \hline & empreendedor & conta-própria & trabalhador \\
& & & \\
tendência & $-0.000212^{* * *}$ & $-0.00233^{* * *}$ & $0.00254^{* * *}$ \\
\multirow{4}{*}{ const } & $(5.92 \mathrm{e}-05)$ & $(0.000111)$ & $(0.000118)$ \\
& $0.483^{* * *}$ & $4.913^{* * *}$ & $-4.396^{* * *}$ \\
& $(0.119)$ & $(0.221)$ & $(0.236)$ \\
\hline
\end{tabular}

Erros padrões robustos em parênteses

*** $p<0.01,{ }^{* *} p<0.05,{ }^{*} p<0.1$ 
A estratificação da proporção de empreendedores pela riqueza é mostrada na Figura 6. Podese perceber que existe uma tendência positiva da proporção de empreendedores mais pobres (com riqueza abaixo da mediana) e uma tendência negativa para proporção mais rica (com riqueza acima da mediana) ao longo do tempo. Novamente, testamos as significâncias estatísticas do comportamento dessas proporções através dos mesmos modos explicados anteriormente. Os testes se encontram nas Tabelas 3 e 4. A significância estatística a $1 \%$ é confirmada para essas proporções, com exceção de $d 2$ para a fração com riqueza abaixo da mediana. Porém ela é confirmada quando se verifica o sinal e sua significância no caso de uma tendência linear.

A mensagem que temos dos dados brasileiros é que observamos uma correlação positiva entre riqueza e empreendedorismo, vista através de regressões não-paramétricas, sugerindo a existência de restrições de crédito. Todavia, um aumento de crédito, como observado no período, levou a uma diminuição do empreendedorismo. Quando estratificada pela riqueza, ocorre um aumento de empreendedorismo para a fração pobre e uma queda para a fração rica. Esses fatos são consistentes com predições teóricas do modelo.

a)

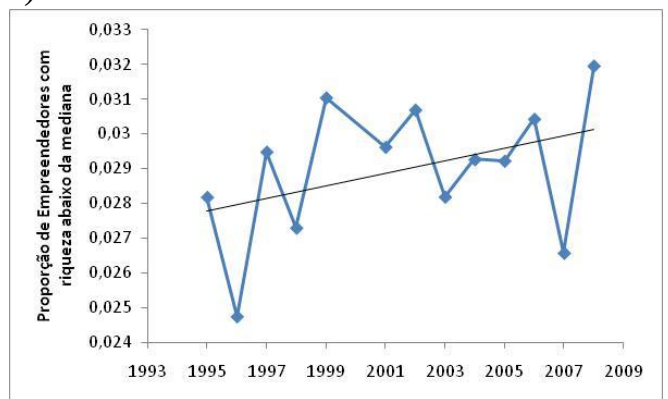

b)

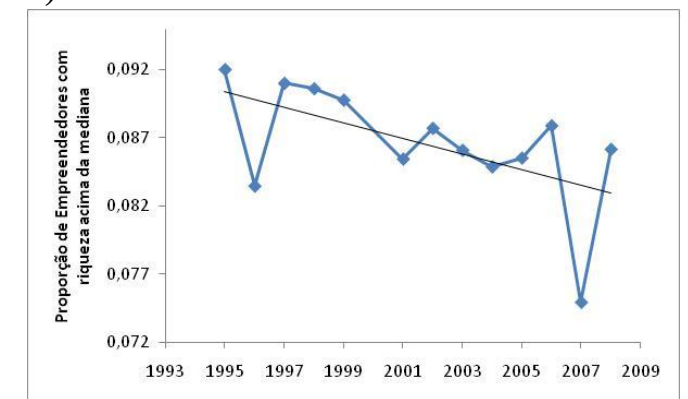

Figura 6: a) Proporção de Empregadores com riqueza abaixo da mediana; b) Proporção de Empregadores com riqueza acima da mediana para o período 1995-2008

Tabela 3: Regressão da proporção de empreendedores com riqueza abaixo e acima da mediana em dummies

\begin{tabular}{|c|c|c|}
\hline & Riqueza<mediana & Riqueza>mediana \\
\hline d2 & $\begin{array}{c}0.000427 \\
(0.000491)\end{array}$ & $\begin{array}{c}-0.00425^{\star * *} \\
(0.000821)\end{array}$ \\
\hline const & $\begin{array}{c}0.0289^{* * *} \\
(0.000359)\end{array}$ & $\begin{array}{c}0.0885^{\star * *} \\
(0.000609)\end{array}$ \\
\hline
\end{tabular}


Tabela 4: Regressão da proporção de empreendedores com riqueza abaixo e acima da mediana em uma tendência linear

\begin{tabular}{|c|c|c|}
\hline & Riqueza<mediana & Riqueza>mediana \\
\hline tendência & $\begin{array}{c}0.000167^{\star * *} \\
(0.000006)\end{array}$ & $\begin{array}{c}-0.000583^{* \star *} \\
(0.000101)\end{array}$ \\
\hline const & $\begin{array}{c}-0.305^{\star *} \\
(0.120)\end{array}$ & $\begin{array}{c}1.253^{* \star *} \\
(0.202)\end{array}$ \\
\hline
\end{tabular}

\section{EXERCÍCIOS NUMÉRICOS}

Através de uma análise computacional, esta subseção estuda quais são os efeitos do aumento de $\lambda$ tomando parâmetros e distribuições que se assemelham aos dados brasileiros. A queda de juros também poderia ser entendida como uma diminuição da restrição de crédito. Todavia, para ser consistente com a idéia de juros exógeno (pequena economia aberta) e com a idéia de uma mudança institucional na política de crédito, acreditamos que a variação do parâmetro de comprometimento limitado seja mais apropriada.

O objetivo é averiguar as implicações do modelo, verificando se este é consistente com as predições teóricas e se consegue reproduzir os seguintes fatos vistos nos dados brasileiros: i) a queda da proporção de empreendedores com riqueza acima de certo nível; ii) o aumento dessa proporção para indivíduos com riqueza abaixo do mesmo nível; iii) a proporção de empreendedores diminui como resultado da menor restrição de crédito; iv) o perfil nãoparamétrico observado nos dados entre as ocupações e riqueza.

A importância dessa seção reside no resultado indeterminado da Proposição 3 e sobre como a proporção de empreendedores se comporta com o aumento de $\lambda$. Como nos dados brasileiros, os exercícios numéricos a seguir mostram que o modelo gera um aumento de proporção de empreendedores para os indivíduos mais pobres e que existe queda de empreendedorismo no efeito agregado da economia 


\subsection{Valores dos parâmetros}

Supõe-se que a tecnologia é da forma

$$
\theta\left[\mathrm{k}^{\alpha} \mathrm{l}^{1-\alpha}\right]^{\gamma}
$$

em que $\alpha \in(0,1)$.

Os valores utilizados para os parâmetros são os seguintes: o montante da renda que vai para capital é 0,3; o valor do parâmetro de "span-of-control" $\gamma$ segue a estimativa 0,85 apresentada por Atkeson et. al. (1996); a taxa de juros é a média da SELIC para o período, 0,20 .

Supomos que talento e riqueza são distribuídos independentemente. A estratégia para a distribuição de riqueza foi a seguinte: i) criou-se um histograma de riqueza em que cada bin tivesse largura de 0,2 ; ii) o número de indivíduos em cada bin é igual ao número de pessoas em determinado bin dividido pelo bin com menor número de pessoas. Retirando o percentil mais rico da amostra, temos que o $\operatorname{supp}(A)=[0,26,9]$. O histograma dessa variável se encontra na Figura 2.

Menos óbvio é o procedimento para a distribuição de talento e para $\lambda$ e $\lambda^{\prime}$. Na literatura, diferentes tratamentos são apresentados para a distribuição de talento empreendedor. Cagetti e De Nardi (2006) supõem uma distribuição com apenas dois valores. Evans e Jovanovic (1989) e Paulson, Townsend e Karaivanov (2006) tomam uma distribuição lognormal. Gollin (2008) parte de uma distribuição beta. Como apontam Paulson, Townsend e Karaivanov (2006), estudos sobre o papel e o formato da distribuição de talento empreendedor são uma prioridade nessa área. Com esse impasse, esse trabalho parte de uma suposição conveniente, em que a distribuição de talento empreendedor segue uma uniforme $\operatorname{com} \operatorname{supp}(\theta)=[0,1]$.

Para $\lambda$, um procedimento correto seria estimar estruturalmente esse parâmetro, como em Evans e Jovanovic (1989) e Buera (2008) para os EUA ou Paulson, Townsend e Karaivanov (2006) para a Tailândia. Madeira (2006) estima esse parâmetro para o Brasil durante o período 1996-1999, o que não permite se valer desses resultados. Sem muito para dizer sobre os valores, esse trabalho simula alguns aumentos desse parâmetro variando tanto o valor 
inicial como o valor final. Os resultados são apresentados na subseção a seguir. Expressamos o fato de, apesar de serem valores arbitrários, os sentidos dos resultados não são sensíveis aos valores adotados.

Com essas formas funcionais, distribuições e valores numéricos para os parâmetros, computamos numericamente o equilíbrio no mercado de trabalho e como o aumento de $\lambda$ se reflete sobre as escolhas ocupacionais. A rotina com o procedimento numérico é brevemente apresentada no Apêndice E.

\subsection{Resultados}

A Tabela 5 mostra a proporção das ocupações e o salário de equilíbrio resultante do aumento do parâmetro de comprometimento limitado sobre as ocupações. Nota-se que, independentemente do valor inicial ou do valor final para $\lambda$, ocorre um aumento do salário e uma queda da proporção de empreendedores, resultados consistentes com os microdados brasileiros $^{16}$. As Figuras 7 e 8 elucidam melhor o resultado e apresentam as diferenças entre o modelo EJ tradicional e o modelo EJ modificado (com a condição de equilíbrio no mercado de trabalho), supondo um aumento de $\lambda=1,0$ para $\lambda^{\prime}=1,25$.

Tabela 5: Aumento de $\lambda$ sobre o salário e as ocupações

\begin{tabular}{c|ccccc} 
& $\boldsymbol{\lambda}=\mathbf{1 , 0}$ & $\boldsymbol{\lambda}=\mathbf{1 , 2 5}$ & $\boldsymbol{\lambda}=\mathbf{1 , 5}$ & $\boldsymbol{\lambda}=\mathbf{1 , 7 5}$ & $\boldsymbol{\lambda}=\mathbf{2 , \mathbf { 0 }}$ \\
\hline UE & 0,0038 & 0,0066 & 0,0092 & 0,0127 & 0,0180 \\
CE & 0,1944 & 0,1833 & 0,1732 & 0,1634 & 0,1534 \\
E & 0,1982 & 0,1899 & 0,1823 & 0,1761 & 0,1715 \\
WW & 0,8018 & 0,8101 & 0,8177 & 0,8239 & 0,8285 \\
salário & 6,8744 & 7,1219 & 7,3100 & 7,4573 & 7,5910
\end{tabular}

No modelo EJ tradicional, um aumento do parâmetro de comprometimento limitado tem dois efeitos. Primeiro, empreendedores que eram anteriormente restritos podem agora investir seu nível de capital ótimo. Segundo, esse aumento muda a condição de seleção apenas para os indivíduos mais pobres, uma vez que os indivíduos mais ricos não são afetados pela restrição de crédito. Dessa forma, o modelo prevê que um aumento em $\lambda$ aumenta apenas o número de

\footnotetext{
${ }^{16} \mathrm{O}$ aumento do salário no modelo é consistente com o aumento da massa salarial durante esse período no Brasil, conforme dados do IPEADATA.
} 
empreendedores na parcela mais pobre da economia, enquanto que a escolha ocupacional não muda para os agentes mais ricos (aqueles que possuem $A>A^{*}$ ).

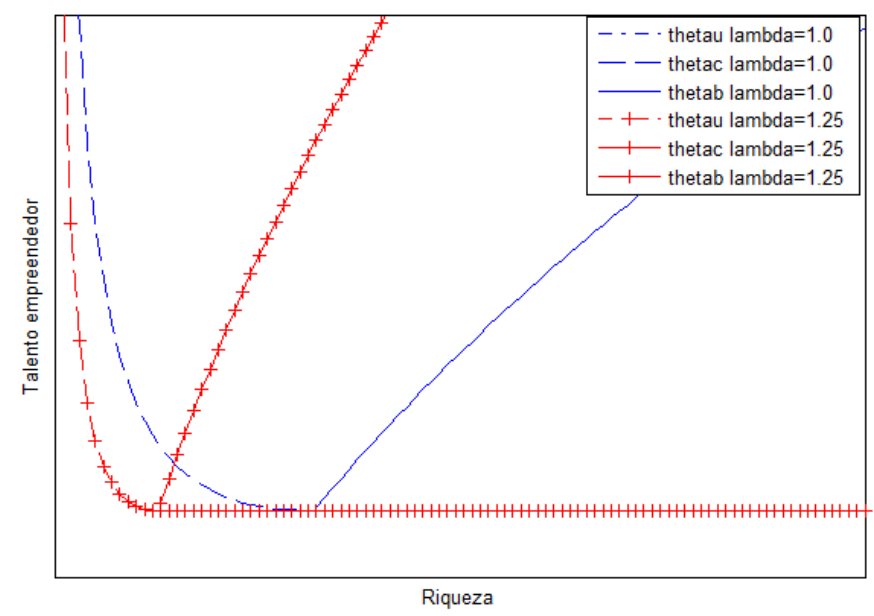

Figura 7: Efeito do aumento de $\lambda$ no modelo EJ tradicional

Uma clara diferença ocorre na Figura 8 que representa modelo EJ modificado. Os dois efeitos presentes no modelo EJ tradicional se mantêm, porém a equação de seleção muda para os indivíduos mais ricos. Esse novo resultado advém da imposição de uma condição de equilíbrio no mercado de trabalho: o aumento de demanda por capital eleva a produtividade marginal do trabalho e, assim, aumenta o salário de equilíbrio. Em equilíbrio, o aumento do salário leva a indivíduos ricos e de baixo talento, antes empreendedores, a optarem pelo trabalho assalariado, enquanto que, trabalhadores pobres e de alto talento, com o afrouxamento da restrição de crédito, optam pelo empreendedorismo, apesar do aumento de salário. A diminuição do número de empreendedores na economia acontece caso exista massa suficiente de agentes ricos. Por fim, a estática comparativa é representada na Figura 9 que relaciona a proporção de empreendedores por nível de riqueza. Note que, conforme $\lambda$ aumenta, a proporção de empreendedores diminui para ricos e aumenta para pobres. No entanto, a queda para ricos é maior proporcionalmente que o aumento para pobres. 


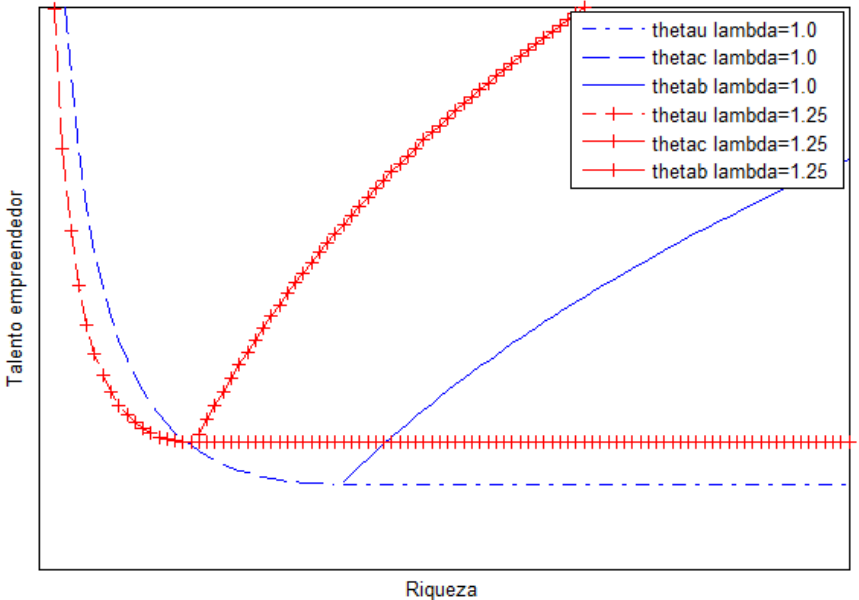

Figura 8: Efeito do aumento de $\lambda$ no modelo EJ modificado

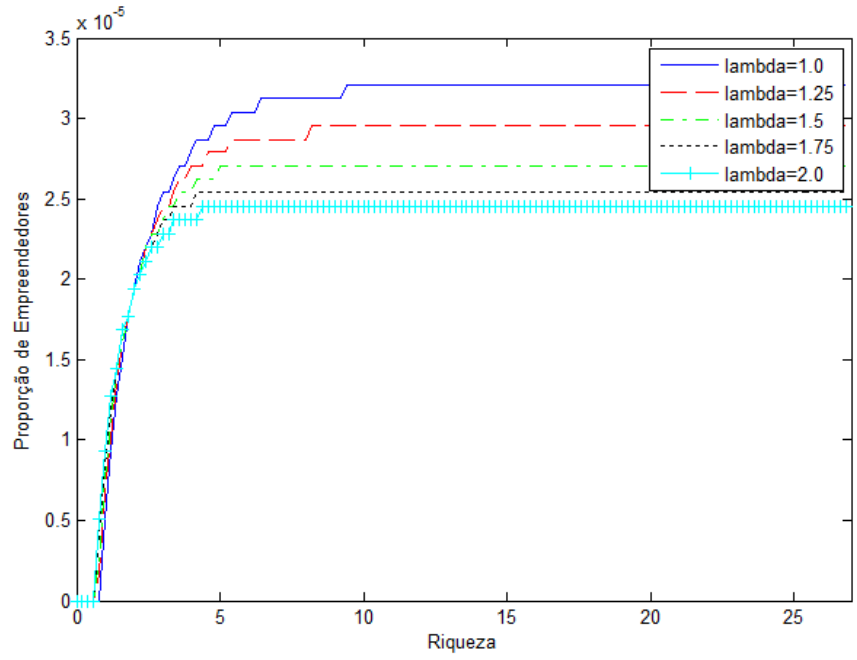

Figura 9: Efeito do aumento de $\lambda$ sobre empreendedorismo por faixa de riqueza

\subsection{Resultados para a extensão com conta-própria}

Para os exercícios numéricos para o modelo com conta-própria, tome $\mu=4, c=0,2$ e a distribuição de $\xi$ como uma uniforme $\operatorname{com} \operatorname{supp}(\xi)=[0,1]$. A Tabela 6 abaixo mostra como as ocupações se modificam com o aumento de $\lambda$. 
Tabela 6: Aumento de $\lambda$ sobre o salário e as ocupações no modelo estendido

\begin{tabular}{c|ccccc} 
& $\boldsymbol{\lambda = 1 , 0}$ & $\boldsymbol{\lambda}=\mathbf{1 , 2 5}$ & $\boldsymbol{\lambda}=\mathbf{1 , 5}$ & $\boldsymbol{\lambda}=\mathbf{1 , 7 5}$ & $\boldsymbol{\lambda}=\mathbf{2 , \mathbf { 0 }}$ \\
\hline UE & 0,0063 & 0,0111 & 0,0171 & 0,0238 & 0,0315 \\
CE & 0,1134 & 0,1020 & 0,0898 & 0,0779 & 0,0661 \\
E & 0,1197 & 0,1132 & 0,1069 & 0,1017 & 0,0976 \\
WW & 0,5196 & 0,5332 & 0,5442 & 0,5509 & 0,5586 \\
SE & 0,3608 & 0,3536 & 0,3489 & 0,3474 & 0,3438 \\
salário & 7,4355 & 7,6641 & 7,8295 & 7,9560 & 8,0520
\end{tabular}

Note que, da mesma forma que o modelo sem a atividade conta-própria, a queda da restrição de crédito aumenta o salário, diminui a proporção de empreendedores e aumenta a proporção de trabalhadores. No entanto, a extensão do modelo oferece outras informações não presentes no modelo base. Primeiro, a proporção de conta-própria diminui ao longo do tempo. Além disso, a extensão do modelo replica os perfis não-paramétrico entre as ocupações e riqueza vistos nas Figuras 10, 11 e 12. Indo de acordo com as regressões não-paramétricas feitas para o Brasil, a proporção de trabalhadores pelo nível de riqueza apresenta o formato de "U" para baixo, indicando que para, essa proporção aumenta para pobres mas, a partir de um certo nível, ela decresce conforme riqueza aumenta. Da mesma forma, a proporção de conta-própria apresenta uma relação negativa com riqueza, característica dessa atividade para países em desenvolvimento.

Por fim, o aumento de $\lambda$, como no modelo base, aumenta o salário e aumenta empreendedorismo para pobres e diminui para ricos, sendo que o efeito combinado diminui essa proporção na economia. Como o salário aumenta e o ganho de conta-própria é fixo, a proporção nessa atividade diminui, indo de encontro com a evidência de que esse ganho pode ser considerado um salário de reserva. 


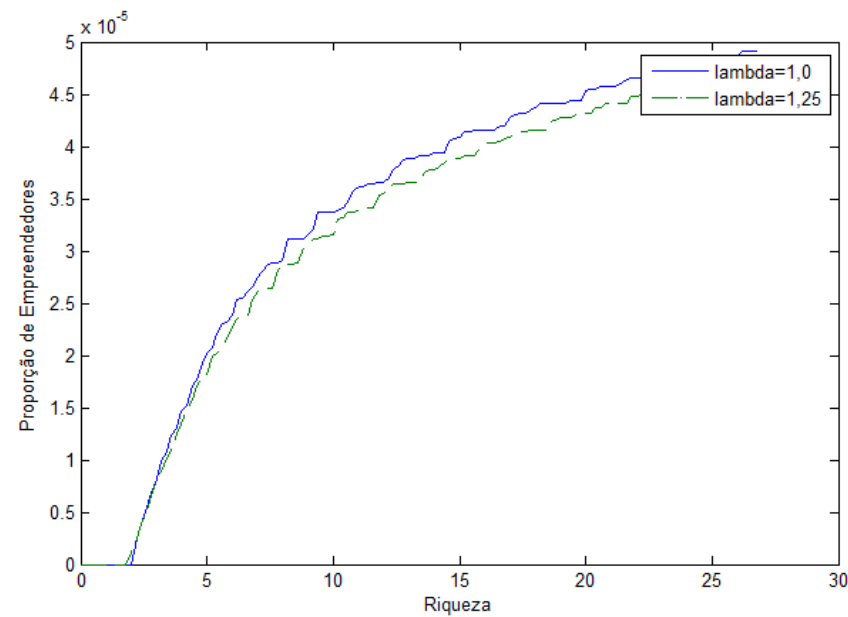

Figura 10: Proporção de Empreendedores pela riqueza

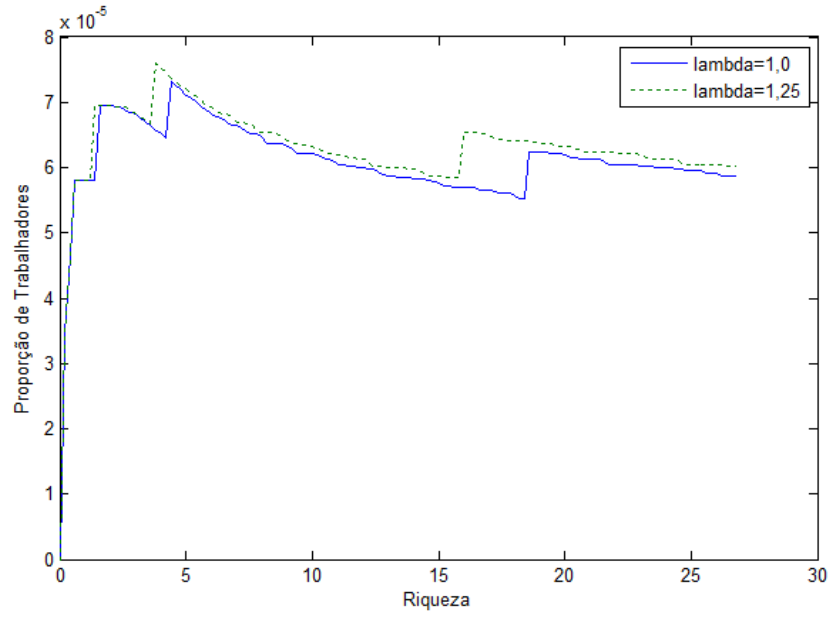

Figura 11: Proporção de Trabalhadores pela Riqueza

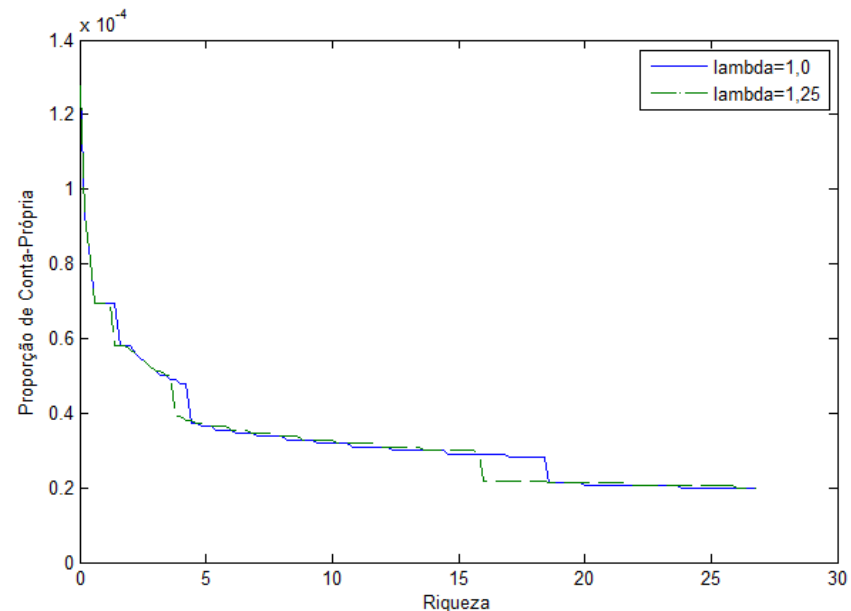

Figura 12: Proporção de Conta-Própria por faixa de riqueza 


\section{CONCLUSÃO}

Este trabalho apresentou um modelo que reconcilia dois fatos aparentemente contraditórios na literatura de empreendedorismo: enquanto microeconomistas de desenvolvimento têm apontado uma correlação positiva entre empreendedorismo e riqueza, macroeconomistas apontam que desenvolvimento (acumulação de riqueza) e empreendedorismo vão em direções opostas.

Estes dois fatos podem coexistir mesmo quando o desenvolvimento é induzido por um afrouxamento da restrição de crédito. $\mathrm{O}$ aumento de crédito ao mesmo tempo em se observa uma queda da proporção de empreendedores é um acontecimento natural quando se tem em mente um efeito de equilíbrio geral. Interessantemente, a diminuição da restrição de crédito possui efeitos heterogêneos quando os agentes são estratificados pela riqueza: a proporção pode crescer para pobres e, com certeza, diminui para ricos. Dessa forma, o efeito da diminuição de restrição de crédito sobre empreendedorismo depende fundamentalmente da distribuição de riqueza. Isso é consistente com microdados brasileiros, país com considerável expansão de crédito recente. Ao adicionar a atividade conta-própria, o modelo mantém as principais predições e ainda é enriquecido pelo fato de se aproximar dos perfis nãoparamétricos vistos nos dados brasileiros.

Esse trabalho sugere futuras pesquisas. Claramente o próximo passo envolve a estimação estrutural do modelo. Dessa forma, poderíamos verificar com maior precisão o ajuste do modelo aos dados brasileiros. As estimativas estruturais nos permitiriam gerar previsões para cenários contrafatuais de afrouxamento de restrição de crédito sobre as ocupações. Além disso, seria interessante estudar outros países que presenciaram expansão de crédito e verificar se o modelo também é consistente com esses dados. 


\section{REFERÊNCIAS BIBLIOGRÁFICAS}

AGHION, Phillipe; BOLTON, Patrick. A Theory of Trickle-Down, Growth and Development

Review of Economic Studies. Vol.64, n.2, p.151-172, 1997.

ARAUJO, Aloisio; FUNCHAL, Bruno. Credit Markets in Brazil: Institutional Reforms and Growth. Mimeo. 2010.

ASSUNÇÃO, Juliano; ALVES, Luciana. Restrições de Crédito e Decisões Intra-Familiares.

Revista Brasileira de Economia. Vol.61, n.2, p.201-229, 2007

BANERJEE, Abhijit; DUFLO, Esther. Do Firms Want to Borrow More? Testing Credit Constraints Using a Directed Lending Program. Mimeo. 2008.

BANERJEE, Abhijit; MOLL, Benjamin. Why Does Misallocation Persist? American Economic Journal: Macroeconomics. Vol.2, n.1, p.189-206, 2010

BANERJEE, Abhijit; NEWMAN, Andrew. Occupational Choice and the Process of Development. Journal of Political Economy. Vol.101, n.2, p.274-298, 1993.

BLANCHFLOWER, David; OSWALD, Andrew. What Makes an Entrepreneur? Journal of Labor Economics. Vol. 16, n.1, p.26-60, 1998.

BUERA, Francisco. Persistency of Poverty, Financial Frictions and Entrepreneurship. Mimeo. 2008.

BUERA, Francisco. A Dynamic Model of Entrepreneurship with Borrowing Constraints: Theory and Evidence. Annals of Finance. Vol.5, n.3, p.443-464, 2009.

COATES, Kenneth; COX, Pamela; CALARI, Cesare. WORLD BANK: CREDIT AND LOAN REPORTING SYSTENS IN BRAZIL. Washington, DC. 2006

CAGETTI, Marco; DE NARDI, Mariacristina. Entrepreneurship, Frictions and Wealth Journal of Political Economy. Vol.114, n.5, p.835-870, 2006. 
ESWARAN, Mukesh; KOTWAL, Ashok. Access to Capital and Agrarian Production Organisation. Economic Journal. Vol.96, n.2, p.482-498, 1986.

EVANS, David; JOVANOVIC, Boyan. An Estimated Model of Entrepreneurship Choice under Liquidity Constraints. Journal of Political Economy. Vol.97, n.4, p.808-827, 1989.

FAZZARI, Steven; HUBBARD, R. Glenn; PETERSEN, Bruce. Financing Constraints and Corporate Investment. Brookings Papers on Economic Activity. Vol.19, n.1, p.141-206, 1988.

GALOR, Oded; ZEIRA, Joseph. Income Distribution and Macroeconomics. Review of Economic Studies. Vol.60, n.1, p.35-53, 1993.

GHATAK, Maitreesh; JIANG, Neville. A simple model of inequality, occupational choice, and development. Journal of Development Economics. Vol.69, n.2, p.205-226, 2002.

GOLLIN, Douglas. Nobody's business but my own: Self-employment and small enterprise in economic development. Journal of Monetary Economics. Vol.55, n.2, p.219-233, 2008.

HOLTZ-EAKIN, Douglas; JOULFAIAN, David; ROSEN, Harvey. Entrepreneurial decisions and liquidity constraints. RAND Journal of Economics. Vol.25, n.2, p.334-347, 1994.

HSIEH, Chang-Tai; KLENOW, Peter. Misallocation and Manufacturing TFP in China and India. Quarterly Journal of Economics. Vol.124, n.4, p.1403-1448, 2009.

HURST, Erik; LUSARDI, Annamaria. Liquidity Constraints, Household Wealth, and Entrepreneurship. Journal of Political Economy. Vol.112, n.2, p.319-347, 2004.

JEONG, Hyeok; TOWNSEND, Robert. Sources of TFP Growth: Occupational Choice and Financial Deepening. Economic Theory. Vol.32, n.3, p.179-221, 2007

JEONG, Hyeok; TOWNSEND, Robert. Growth and Inequality: Model Evaluation Based on an Estimation-Calibration Strategy. Macroeconomic Dynamics. Vol.12, n.12, p.231-284, 2008.

JUDD, Kenneth. Numerical Methods in Economics. Cambridge, MA: MIT Press,1999. 
KEHOE, Timothy; LEVINE, David. Debt-Constrained Asset Markets. Review of Economic Studies. Vol.60, n.3, p.865-888, 1993.

LUCAS, Robert. On the Size Distribution of Business Firms. The Bell Journal of Economics. Vol.9, n.2, p.508-523, 1978.

MADEIRA, Gabriel. Effects of a Financial Crisis on Occupational Choice: An Empirical Evaluation. Mimeo. 2006.

MONDRAGÓN-VÉLEZ, Camillo; PEÑA-PARGA, Ximena. Business Ownership and SelfEmployment in Developing Economies: The Colombian Case. NBER Volume in International Differences in Entrepreneurship, 2008.

PAULSON, Anna; TOWNSEND, Robert. The Nature of Financial Constraints: Distinguishing the Micro Underpinnings of Macro Models. Mimeo. 2001.

PAULSON, Anna; TOWNSEND, Robert. Entrepreneurship and Financial Constraints in Thailand. Journal of Corporate Finance. Vol.10, n.2, p.229-262, 2004.

PAULSON, Anna; TOWNSEND, Robert; KARAIVANOV, Alexander. Distinguishing Limited Liability from Moral Hazard in a Model of Entrepreneurship. Journal of Political Economy. Vol.114, n.1, p.100-144, 2006.

SILVERMAN, Bernard. Density Estimation for Statistics and Data Analysis. Boca Raton, FL: Chapman \& Hall/CRC, 1986.

TAVERAS, Carmen. Entrepreneurship, Learning and Wealth. Mimeo. 2009. 


\section{APÊNDICES}

\section{Apêndice A - Modelo}

Prova da Proposição 2: A prova consiste em dois passos.

Passo 1: Tome um salário $w$ e um indivíduo $(\bar{\theta}, \bar{A})$, com função lucro $V_{E}(\bar{\theta}, \bar{A}, w)$. Tome outro salário $w^{\prime}<\min \left\{w, V_{E}(\bar{\theta}, \bar{A}, w)\right\}$. Dado $(\theta, A) \geq(\bar{\theta}, \bar{A})$, temos que $V_{E}\left(\theta, A, w^{\prime}\right)>w^{\prime}$. Defina a demanda desses indivíduos como $\bar{l}=\int_{\bar{A}}^{+\infty} \int_{\bar{\theta}}^{+\infty} l\left(\theta, A, w^{\prime}\right) f(\theta, A) d \theta d A$. Tome $(\overline{\bar{\theta}}, \overline{\bar{A}})<(\bar{\theta}, \bar{A})$ tal que $\int_{0}^{\overline{\bar{A}}} \int_{0}^{+\infty} f(\theta, A) d \theta d A+\int_{\overline{\bar{A}}}^{+\infty} \int_{0}^{\overline{\bar{\theta}}} f(\theta, A) d \theta d A<\bar{l} . \exists w^{\prime \prime}<w^{\prime}$ tal que $V_{E}\left(\overline{\bar{\theta}}, \overline{\bar{A}}, w^{\prime \prime}\right)>w^{\prime}$. Como temos uma função densidade que caracteriza os agentes, isso nos garante uma demanda agregada excedente positiva.

Passo 2: Tome $w$. Pela Hipótese 1, temos que $\lim _{\theta \rightarrow \infty} \int_{0}^{+\infty} \int_{\theta}^{+\infty} l(\theta, A, w) f(\theta, A) d \theta d A=0$ para $\forall w$. Tome um nível de talento $\bar{\theta}$. Defina $\bar{n}=\int_{0}^{+\infty} \int_{0}^{\bar{\theta}} f(\theta, A) d \theta d A$. Pela Hipótese 1 , $\exists \overline{\bar{\theta}}, \overline{\bar{\theta}}>\bar{\theta}$ tal que $\int_{0}^{+\infty} \int_{\overline{\bar{\theta}}}^{+\infty} l(\theta, A, w) f(\theta, A) d \theta d A<\bar{n}$. O lucro desses indivíduos é $V_{E}(\overline{\bar{\theta}}, w)$. Tome $w^{\prime}>\max \left\{w, V_{E}(\overline{\bar{\theta}}, w)\right\}$. Esse aumento de salário nos garante que aumenta a fração de indivíduos trabalhadores e a fração de empreendedores diminui, sendo que a demanda por trabalho também diminui para o empreendedores remanescentes.

O Passo 1 nos garante que, para um determinado nível de salário, existe excesso de demanda por trabalho. O Passo 2 nos garante que existe um nível de salário tal que existe excesso de oferta de trabalho.

Pelo Teorema do Máximo, a função demanda de trabalho de cada indivíduo é contínua em $w$. Como os indivíduos são caracterizados por uma função densidade de probabilidade, a função de demanda agregada é contínua. Pelo Teorema do Valor Intermediário, $\exists w^{*}$ tal que $z\left(w^{*}\right)=0$. 
Apêndice B - Estatísticas descritivas

Tabela B1: Estatísticas descritivas separadas por ocupações

média desvio-padrão mediana

Anos de educação

\begin{tabular}{cccc} 
Empregador & 10,824 & 4,191 & 12 \\
Conta-Própria & 7,731 & 4,207 & 7 \\
Trabalhador & 10,042 & 4,093 & 12 \\
& & & \\
\cline { 2 - 3 } & média & desvio-padrão mediana \\
\hline
\end{tabular}

Renda do trabalho

Empregador

$4,145 \quad 6,350 \quad 2,442$

Conta-Própria

$1,186 \quad 1,920 \quad 0,651$

Trabalhador

$1,313 \quad 1,884 \quad 0,764$

média desvio-padrão mediana

Riqueza

\begin{tabular}{cccc} 
Empregador & 9,398 & 14,26834 & 6,22039 \\
Conta-Própria & 4,778 & 6,30546 & 3,55365 \\
Trabalhador & 5,076 & 6,382061 & 3,86496 \\
\hline
\end{tabular}




\section{Apêndice C - Medida de riqueza}

A medida de riqueza é baseada em Madeira (2006). Esta medida foi construída como a soma de três componentes: rendimentos de ativos financeiros, renda de aluguel de outros imóveis e o valor estimado da casa em que reside. Rendimentos de aluguel de outros imóveis e de ativos financeiros são obtidos diretamente da PNAD. O valor desses rendimentos para cada indivíduo foi tomado como sendo a média desses valores para indivíduos dentro do mesmo domicílio $^{17}$. Já o valor da casa foi estimado pelo valor de aluguel pago por pessoas que moram em casas alugadas, dadas as características e localização do imóvel.

As características do domicílio utilizadas para fazer esse matching foram: material das paredes, material do telhado, tipo de domicílio (se apartamento ou casa), número de cômodos, disponibilidade de água encanada, existência e uso do banheiro, escoadouro, tipo de coleta de lixo e iluminação do domicílio. Para a localização, consideramos a unidade federativa e a área em que se encontra o imóvel (urbano ou rural e metropolitano ou não). Além disso, consideramos a existência de alguns bens duráveis: fogão, geladeira, freezer e máquina de lavar. O valor estimado da casa é a média do aluguel pago por moradores de casas com as mesmas características.

Todavia, devido ao grande número de variáveis, mais de $60 \%$ das casas não tiveram matching: por exemplo, não existe ninguém que more em uma casa alugada com mais de dez cômodos. A saída foi realizar uma regressão linear do valor de aluguel pago sobre as características dos imóveis, para cada ano separadamente, e assim extrapolar os valores estimados para as casas que não tiveram esse matching. Números negativos para os valores preditos das casas não passaram de $1 \%$ ao ano. Esses indivíduos foram retirados da amostra.

Para manter os valores de riqueza comparáveis ao longo dos anos, dividimos o seu valor pela média anual ${ }^{18}$. Como a quase totalidade da medida de riqueza advém do valor da casa, consideram-se apenas indivíduos com casa própria (entre $81 \%-84 \%$ da amostra no período considerado). Isso nos dá uma medida aproximada do valor de fluxo da riqueza. Para

\footnotetext{
${ }^{17}$ A medida de riqueza em que o valor do rendimento de aluguel e juros é a soma desses valores dentro do domicílio também foi construída. A correlação entre essas duas medidas é maior que $98 \%$ ao ano.

${ }^{18}$ Ao invés de normalizar pela média do período, outra medida de riqueza foi normalizada pelo IPCA com anobase 1995. Os resultados foram robustos à medida escolhida.
} 
transformar em estoque, dividimos pela média da taxa de juros para o período (aproximadamente $20 \%)^{19}$.

\footnotetext{
${ }^{19}$ A taxa de juros utilizada é a SELIC, a taxa de juros básica da economia brasileira.
} 
Apêndice D - Não-paramétrico

\section{D.1 - Perfil não-paramétrico de riqueza}
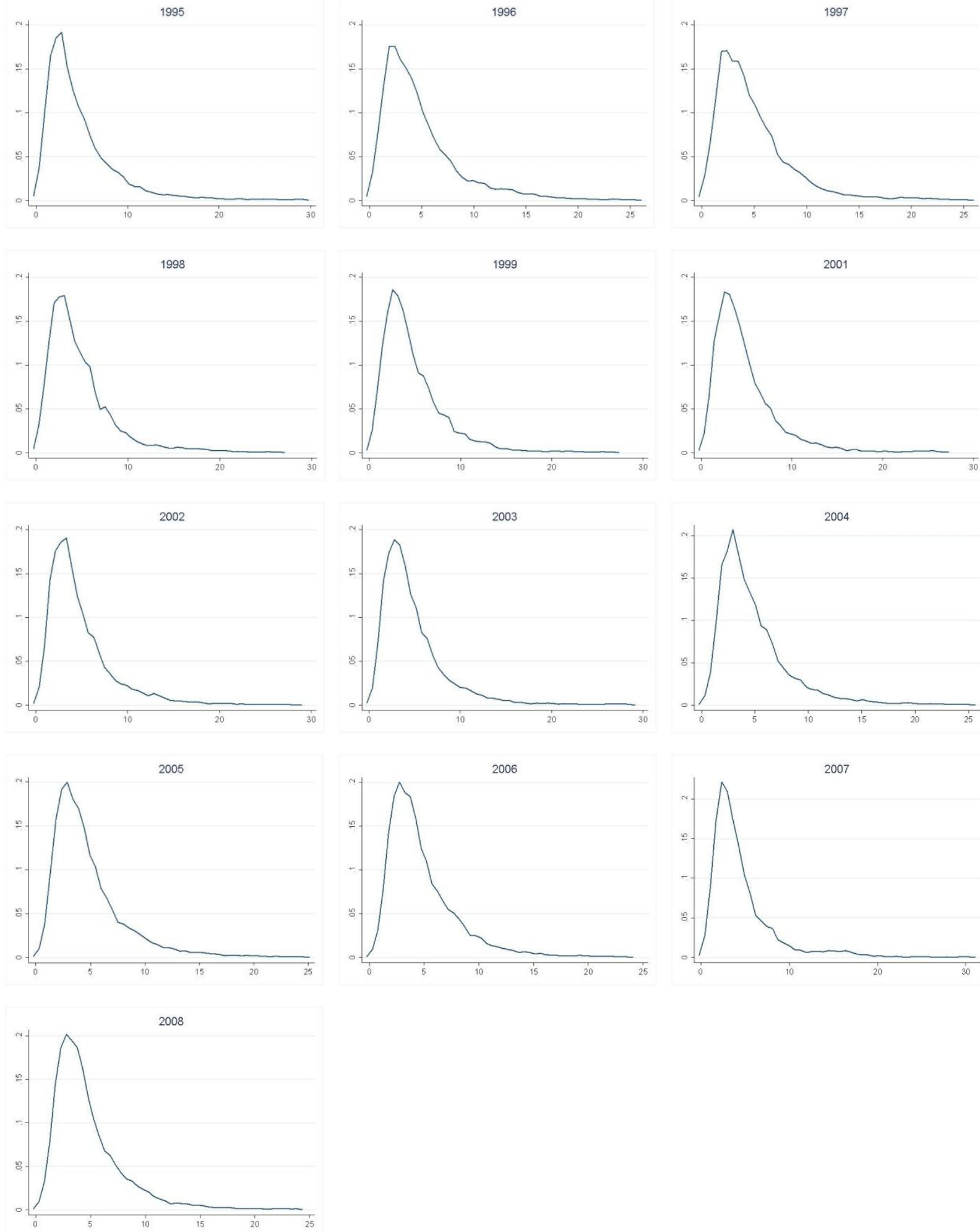

Figura D1: Perfil não-paramétrico de riqueza separado por ano 


\section{D.2 - Regressão não-paramétrica entre empreendedorismo e riqueza}
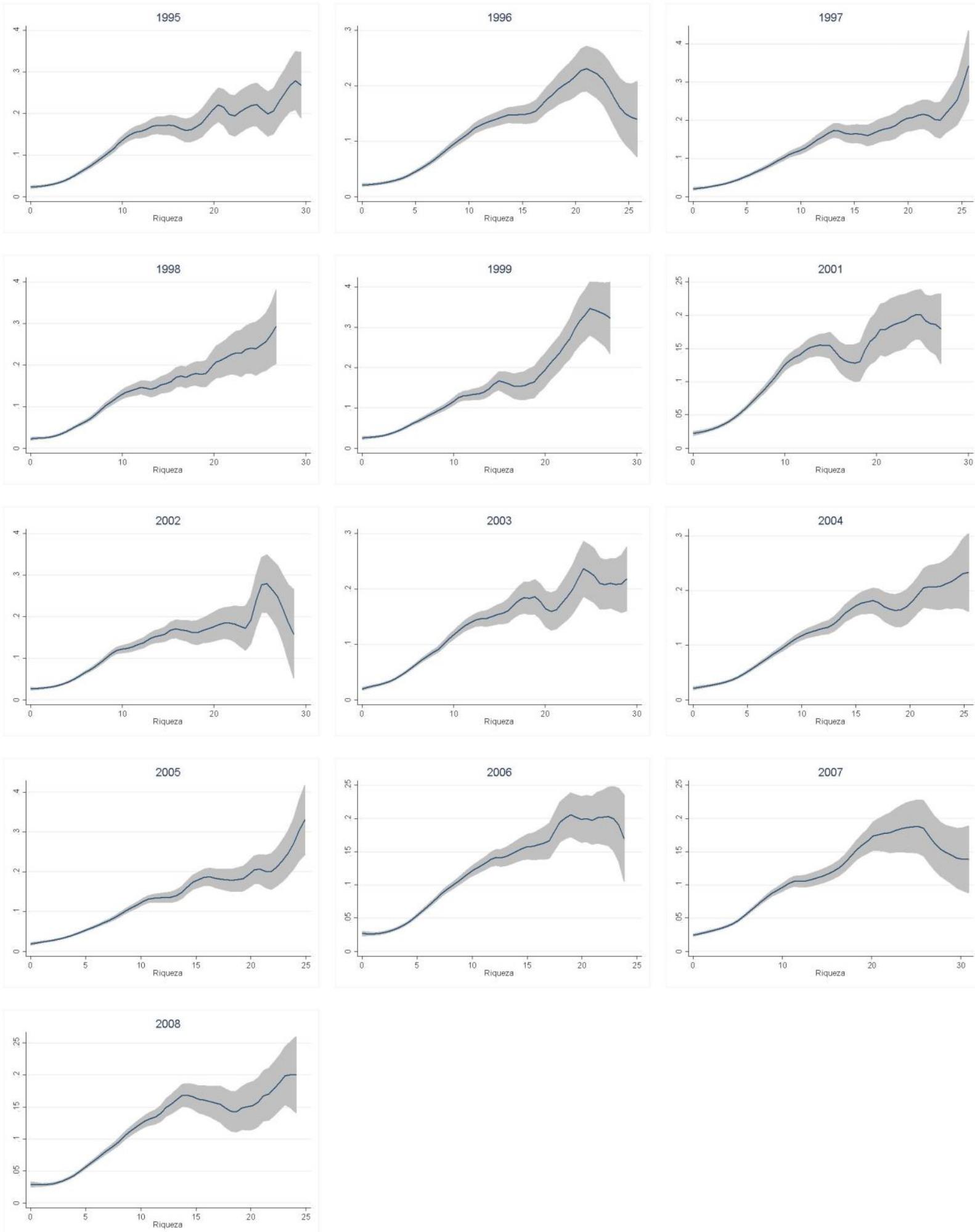

Figura D2: Regressão não-paramétrica entre empreendedorismo e riqueza separada por ano 


\section{D.3 - Regressão não-paramétrica entre empreendedorismo e riqueza para jovens}
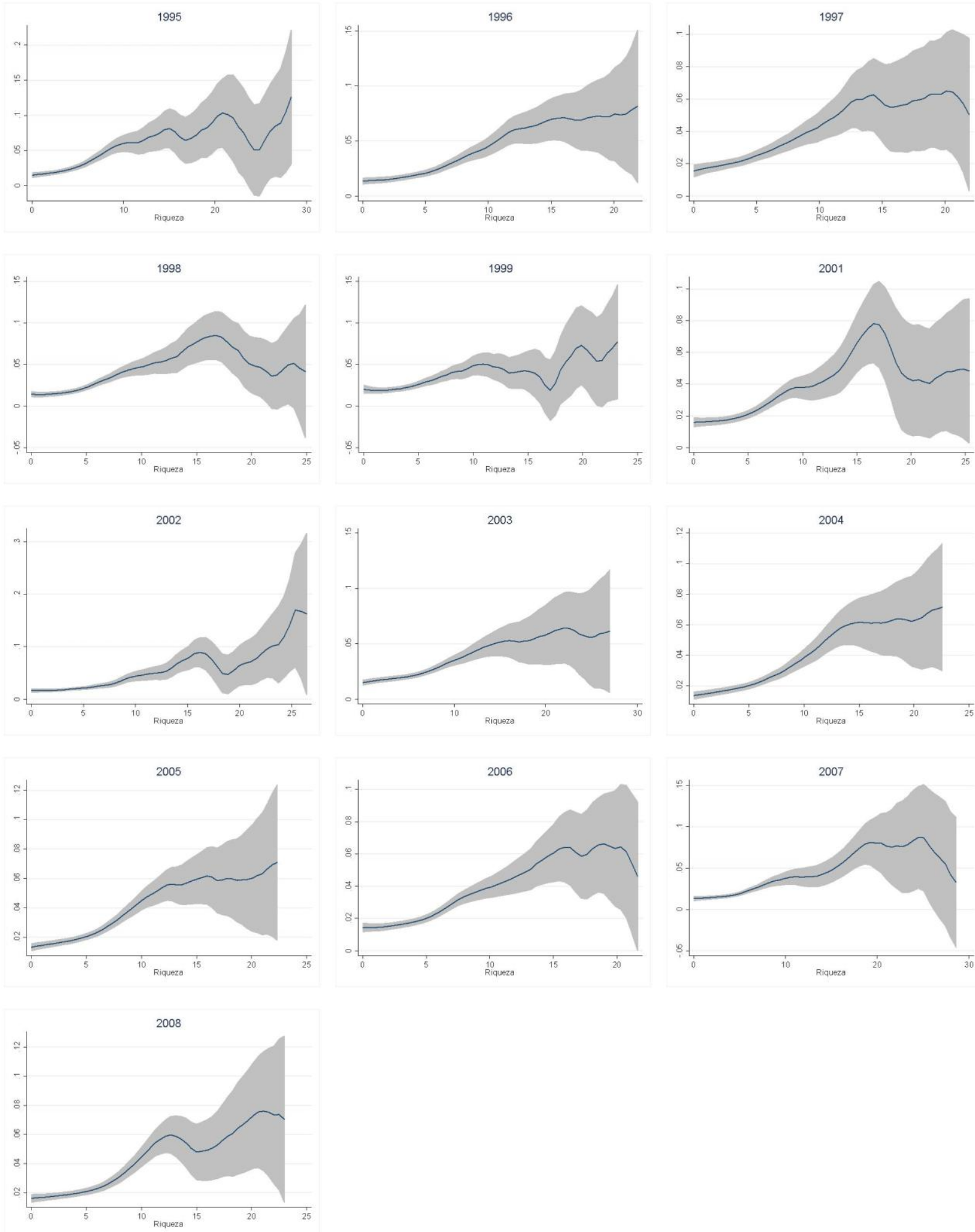

Figura D3: Regressão não-paramétrica entre empreendedorismo e riqueza para pessoas jovens separada por ano 


\section{Apêndice E - Algoritmo}

A rotina se assemelha com o método da Bisseção para encontrar a raiz de uma equação, como apresentado em Judd (1998). A rotina construída para encontrar o salário de equilíbrio é a seguinte:

1) Construa um grid para talento e riqueza com suporte $[0,1]$ e $[0,26.9]$, respectivamente. A distância entre os pontos do grid de talento é 0,05 . O grid de riqueza é ponderado pela proporção de indivíduos com riqueza naquele ponto, conforme o histograma originado dos microdados, em que cada bin tem tamanho 0,2 .

2) Tome um valor inicial para o salário $w^{0}$.

3) Compute uma matriz separando os indivíduos em restritos $\theta>\theta_{b}(A, w)$ e irrestritos $\theta \leq$ $\theta_{b}(A, w)$.

4) Dado esse salário, compute uma matriz de funções valores para trabalhador e empreendedor. Os indivíduos escolhem as ocupações que possuem maiores ganhos.

5) Com $w^{0}$ e essa distribuição de ocupações, compute a demanda agregada (soma da demanda dos empreendedores restritos com a demanda dos empreendedores irrestritos) e a oferta agregada.

6) Caso exista excesso de demanda, aumente o salário. Caso contrário, diminua o salário. Continue os passos 1 a 5 até que o módulo da diferença entre oferta agregada e demanda agregada seja menor que $10^{-3}$. 